\title{
Article \\ GoZone: A Numerical Model for Travelling Fires Based on Cellular Automata Concept
}

\author{
Antonio Gamba * (D) and Jean-Marc Franssen \\ UEE Department, Liege University, 4000 Liege, Belgium; jm.franssen@uliege.be \\ * Correspondence: antonio.gamba@uliege.be
}

Citation: Gamba, A.; Franssen, J.-M. GoZone: A Numerical Model for Travelling Fires Based on Cellular Automata Concept. Appl. Sci. 2021, 11, 10679. https://doi.org/ $10.3390 /$ app 112210679

Academic Editors: Luis Laim, Aldina Santiago and Nicola Tondini

Received: 1 October 2021

Accepted: 9 November 2021

Published: 12 November 2021

Publisher's Note: MDPI stays neutral with regard to jurisdictional claims in published maps and institutional affiliations.

Copyright: (c) 2021 by the authors. Licensee MDPI, Basel, Switzerland. This article is an open access article distributed under the terms and conditions of the Creative Commons Attribution (CC BY) license (https:// creativecommons.org/licenses/by/ $4.0 /)$.

\begin{abstract}
Fires in large compartments tend to burn locally and to move across the floor over a period of time; this particular behaviour has been discovered to challenge the assumption of uniform gas temperature in the fire compartment. Recent studies on fires in large compartments have led to the now widely known concept of "travelling fires". Several models have been proposed to describe the evolution in time of travelling fires. Although these models represented an innovative step in the field of travelling fires, the major drawbacks of these models can be found in the simplification of fire dynamics (constant spread rate, 1D imposed fire path) and limited field of application (rectangular based geometries). The purpose of this paper is to present a numerical model of travelling fire. The model was based on an improved zone model combined with a cellular automata model. The software GoZone, in which the model was implemented, is intended to be a practical solution to analyse fires in large compartments of potentially any shape. GoZone is aimed to describe the complex dynamics of the fire from ignition to a phase of growing localised fire that may eventually travel in the compartment, possibly followed by a flashover. The main sub models comprising GoZone are presented. A comparison is given with the results of under ventilated fire test 2 of the BST/FSR 1993 test series and with respect to the Veselì travelling fire test is shown. GoZone shows a promising capacity to represent fires in a large compartment in both air and fuel controlled fire conditions.
\end{abstract}

Keywords: travelling fire; fire dynamics; numerical fire model

\section{Introduction}

Knowledge about fire development in buildings, particularly the concept of compartment fire, was developed during the decades in between 1960 and 1990. An important contribution was made by Kawagoe [1] and thereafter by Thomas [2]. The first author gave a definition of compartment fire, and through observations was able to define the link between gas phase temperature, burning rate, and ventilation. The second author, by extending and formalizing the work of Kawagoe, provided a series of formulations to estimate the fire duration and temperature, the latter was supposed to be uniform in the compartment. From the 70s onward, research was focused on refining the knowledge acquired from Thomas and Kawagoe as well as trying to translate this into design methodologies with an emphasis on structural performance $[3,4]$. Between the early 90 s and in the first decade of the new millennium, uniform burning assumptions have been challenged by experimental fire tests, which have shown that in compartments with larger floor areas, the temperature distribution is not uniform [5]. Combustion does not occur simultaneously through the whole floor of the compartment; it tends to be limited to some portions of the floor and the position of these burning zones changes over time. These fires have been labelled as "travelling fires" [6].

The discipline of structural fire engineering has seen dramatic progress since the early 2000s. Nowadays, it is possible to model the behaviour of complex structures subjected to fire by nonlinear finite element software $[7,8]$. However, when it comes to the representation 
of the fire that attacks the structure, practically, the applicable engineering solutions are essentially limited to compartments in which a fully developed fire is raging or, at best, to compartments where the situation is characterised by a horizontal stratification in two zones (zone models): an upper layer containing hot combustion products and a lower layer of clear air $[9,10]$. To date, few models have been proposed for localised fires. The first is a correlation model developed by Heskestad [11], giving the temperature evolution in the plume centreline when the flame is not impacting the ceiling. There is no information given yet on how this temperature has to be used to estimate the heat flux to structural elements that are not exactly on the centreline of the plume. The second is the correlation model based on the experimental work performed in Japan by Hasemi, which provides the incoming heat flux received at the ceiling level when the flame is impacting the ceiling [12]. There is no information on how this flux has to be used for structural elements such as beams that are underneath the ceiling. A third model, more numerical, has been developed recently based on the computation of view factors from a solid flame to structural elements. This model can, at this stage, be used for any position of the structural elements, but it completely disregards the presence of the hot zone layer that will develop underneath the ceiling $[13,14]$.

Computational fluid dynamics software have been developed to model the development of fire in building compartments [15]. Such models are extensively used in research projects, but the level of expertise and the CPU time that is required to run such software restricts their use in practical engineering problems to very large projects with consequent budgets. Even then, irrespective of budget considerations, the amount of time needed for each run, typically in the order of several days, does not make such models the best tool for parametric analyses, multiple scenario considerations, or when modifications are made to the compartment during the course of the project.

In the last decades, many authors have proposed simple travelling fire models to address the non-uniform temperature distribution and the fact that burning zones are moving in compartment fires.

In an unpublished internal report "Fire Models for Large Firecells" [16], Clifton proposed an approach in which he applied specific fire models to develop temperaturetime relationships specifically for travelling fires: the Large Firecell Method. Although this pioneering model introduced aspects that are not considered in the conventional uniform burning assumption, it was not widely used in civil engineering, possibly because of insufficient experimental validation [17].

In 2007, Rein et al. proposed an alternative methodology for fuel controlled travelling fire, derived from a series of computational fluid dynamics (CFD) analyses in conjunction with engineering simplifications [18]. The main feature of the model is the proposal of a near field (fire plume) and a far field (hot smoke layer). This model was further developed by Stern-Gottfried and put forward as a design methodology [6]. For the near field, a uniform conservative temperature of $1200^{\circ} \mathrm{C}$ was initially assumed. Afterward, Rackauskaite further improved Rein's model by taking into account more localised fire dynamics, considering realistic fire spread rates, which, as a consequence, reduced the range of possible fire sizes that must be considered [19]. Within this framework, the user must parametrically assess a range of various fire sizes, irrespective of the compartment ventilation, under the assumption of a rectangular compartment with a $1 \mathrm{D}$ travelling direction at a constant spread rate. Subsequently, a new model was developed and implemented by Dai et al. [20]. This model was based on Hasemi's localised fire model for the near field and a zone model for the far field. The temperature was evaluated step by step and considers the smoke layer evolution and its accumulation during the fire. In this model, the fire model is also based on a predetermined one-dimensional fire path (typically, the fire is "circling" around a central core in a rectangular floor plan area).

In Clifton's model, the proposed models to assess travelling fires are only suitable for specific geometrical configurations, often limited to rectangular compartments. The fire is imposed to "travel" through the compartment with a velocity that is constant in 
each analysis and a fire path that is predefined. The practical range of application results are limited. Moreover, experimental evidence has been found on the possibility of a travelling fire under a ventilated condition [21]. This underlines the necessity to overcome the oversimplified assumption adopted in the first travelling fire models where the fire is assumed to be fuel controlled [22].

The aim of this paper is to present a numerical model that combines the concept of zone model with one of cellular automata. The software GoZone in which the model has been implemented is intended to be a practical solution to analyse fires in large compartments of any shape (see Appendix A). It aims to describe the essential features of the fire dynamics from ignition to a phase of localised fire that may travel in the compartment, possibly followed by a flashover, with a specific strategy to take into account under ventilated fire conditions.

\section{Overview of the Model}

The model aimed to describe the fire dynamics and its evolution in time throughout the compartment, accounting for the interactions between the fire and the compartment in terms of energy and mass balance during the course of the fire event.

The fire dynamics and evolution in time are described by a family of models called cellular automata (CA). CA models are used to solve a wide range of problems applying the main idea proposed by Neumann [23] and further detailed by Wolfram [24]. CA models have recently found applications in simulating fire spreading in forest and wildland fires [25-27]. CA models are generally characterised by:

- A physical environment, which is made of a discrete lattice of cells of approximately equal area, called grid, in two dimensional problems. The lattice defines the domain in which CA is applied and computed. The physical environment here is the fire compartment, the floor of which is described with triangular and/or quadrilateral cells in a structured or unstructured manner. In GoZone, the discretisation can be made through a graphical user interface based on the open source mesh generator GMSH [28]. The same discretisation is mirrored up and assigned to the lower plane of the smoke layer Figure 1. The versatile character of unstructured triangular meshes makes it possible to model any shape for the plan view of the compartment, while structures of quadrilateral meshes may be used in more regular geometries such as, for example, rectangular compartments.

- The cell's states, where each cell composing the lattice has a proper state that can change in time. Change in state can be referred to a single cell or to all cells composing the lattice. The cell's state is here: burning or not. Moreover, cells are characterised with properties such as fuel load density, fire growth rate, rate of heat release density, and height of the fuel must be defined in GoZone. While the cell state can be viewed as an "on" or "off" state, a cell property is a given input of the model.

- A local transition rule, which acts upon a cell and can generate a change of state from one discrete time step to the next. The transition rule enabling a change in state of a cell from not burning to burning is described by an ignition strategy (Section 3), while a change in state of a cell to air controlled is defined here by the combustion strategy that is presented in Section 6.

- The cells' neighbourhoods. For each cell in the lattice, there is a neighbourhood that locally influences the evolution of the cell via the transition rule. The cells' neighbourhoods here are all the burning cells on the floor and the cells of the smoke layer showed that radiation to the cell is not obstructed by walls (eventual internal walls or core and, also, external walls in the compartments of non-convex shapes). 


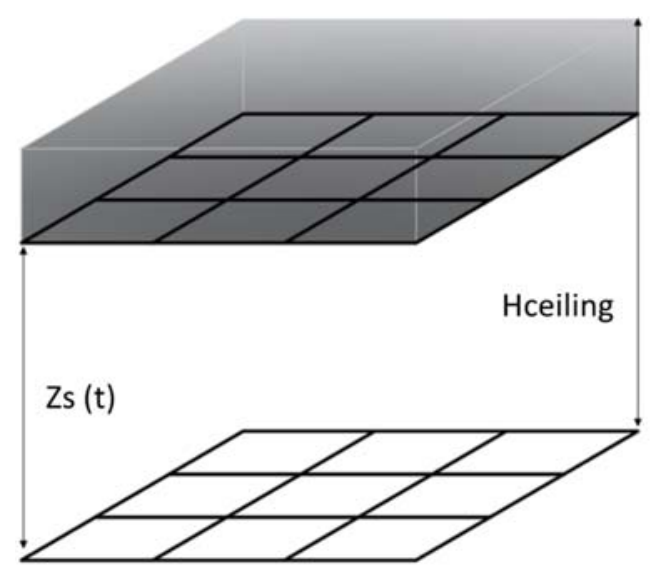

Figure 1. Smoke layer discretisation.

The evaluation of energy and mass balance in the compartment is performed by the well-known 2 zone model OZone [9]. Therefore, quantities such as the time dependent thickness of the smoke layer $Z_{s}$ and its temperature $T_{s}$ are obtained.

\section{Ignition Strategy}

Unlike what has been done in previous travelling fire models $[16,18,20]$, the fire dynamics in GoZone is not imposed by assigning a predefined fire velocity or fire path; instead, it is regulated by the ignition strategy that is presented here.

Development and validation of this strategy was based on experimental data obtained on wood, first because wood-based products still represent a substantial fraction of the fire load in buildings, but also because of the wide availability of scientific data for this specific material. Conceptually speaking, it should be possible to adapt the model for other materials, assuming the availability of data on these materials. Application of the model in a compartment containing different materials would then require defining a combination rule, taking into account the proportion of each material present in the compartment. It will be shown in Section 5 that the proposed ignition strategy can be applied to replicate the global results in terms of ignition and propagation velocity as defined by a time constant linked to each type of occupation in EN1991-1-2,without any reference to the types of material that are present in the compartment.

Theories and models about the ignition of wood have evolved since the first studies started more than one century ago [29] from a concept of critical oven temperature [30] to the introduction of the time of exposure [31] and surface temperature [32-34], then to the idea of a constant incident heat flux [14,15,35-40]. To study materials under constant incident heat flux exposure, a concept of critical heat flux " $q_{c r}$ " was introduced: a constant flux level below which ignition cannot be obtained in practical conditions. However, this concept is based on a constant applied heat flux, not representative of a real fire. An ignition strategy considering a non-constant heat flux would thus probably be more appropriate to represent a real fire. One of the first works on time varying heat flux is from Bilbao et al. [41], who were still using a time decreasing heat flux, which is not representative of the first growing phase in a compartment fire. In 2006, Ji et al. [42] proposed a simple method to derive the time of wood ignition based on linearly increasing heat flux exposition.

The ignition strategy proposed here is based on the notion of critical energy (i.e., the minimum energy needed to be accumulated by a specific material to get ignited) and has been developed from a material characterisation in terms of ignitability, accounting for several kinds of time varying heat flux exposures. The concept is similar to the one used in the cumulative flux method [43] or in the flux time product (FTP) developed mainly for constant heat flux exposure [37]. 


\subsection{Methodology}

A series of 1D numerical analyses were made using SAFIR [7] with a wood semiinfinite media exposed to several laws of radiation exposure until the moment when the surface temperature reaches $350{ }^{\circ} \mathrm{C}$, assumed as the ignition temperature [34,44]. The material was wood from EN 1995-1-2 [45] with a moisture content of $10 \%$, a density of $450 \mathrm{~kg} / \mathrm{m}^{3}$, a coefficient of convection of $25 \mathrm{~W} / \mathrm{m}^{2} \mathrm{~K}$, and an emissivity of 0.8 . For each simulation, a critical energy $E_{c r}$ is computed according to Equation (1).

$$
E_{c r}=\int_{0}^{t_{i g n}}\left(q^{\prime}(\mathbf{t})-q_{c r}\right) d t
$$

where $t_{\text {ign }}$ is the time of ignition (surface temperature $=350{ }^{\circ} \mathrm{C}$ ); $t$ is the time; $q^{\prime}$ is the applied heat flux; and $q_{c r}$ is the critical heat flux.

\subsection{Results}

In Figure 2, some of the flux exposure laws used are shown up to the computed ignition time. For a constant heat flux, exposure of $12.5 \mathrm{~kW} / \mathrm{m}^{2}$ ignition has not been observed, thus the critical heat flux was set at $12.5 \mathrm{~kW} / \mathrm{m}^{2}$. This is in line with what has been observed by Spearpoint [46].

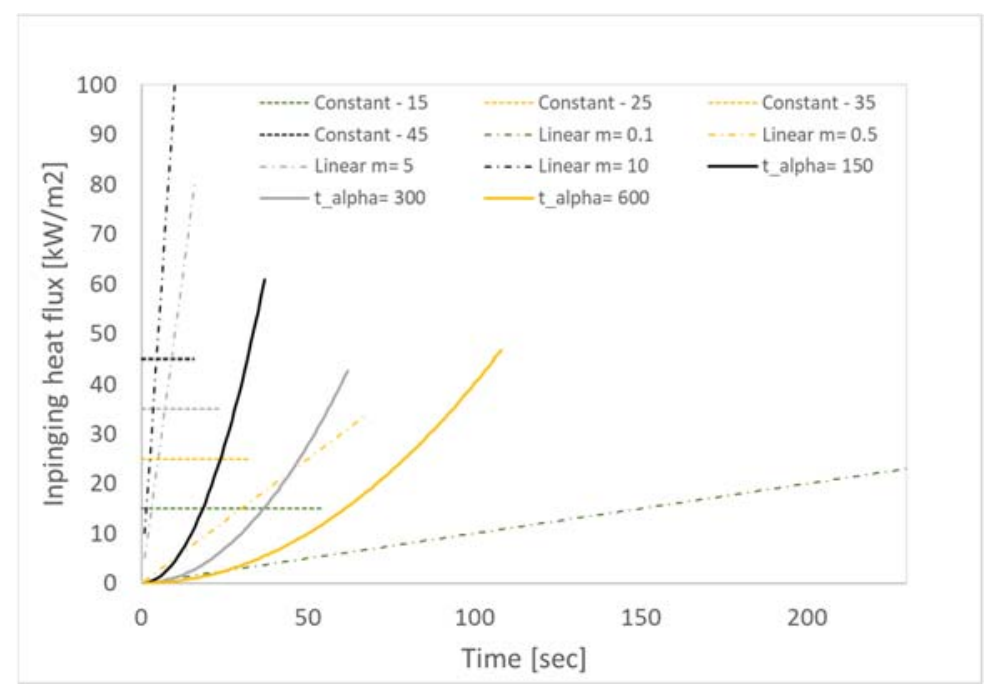

Figure 2. Flux exposure laws used up to time of ignition.

Table 1 shows the different values of constant heat flux exposure; the time of ignition was numerically computed and the critical energy obtained using Table 1.

Table 1. Constant heat flux exposure.

\begin{tabular}{ccc}
\hline Incident Flux $\left[\mathbf{k W} / \mathbf{m}^{2}\right]$ & $\begin{array}{c}t_{\text {ign }} \text { from Numerical } \\
\text { Simulation }[\mathbf{s}]\end{array}$ & $E_{c r}\left[\mathbf{k J} / \mathbf{m}^{2}\right]$ \\
\hline 12.5 & No Ignition & $/$ \\
15 & 3600 & 9000 \\
25 & 54.2 & 677 \\
30 & 32.7 & 572 \\
35 & 24.2 & 545 \\
40 & 19.4 & 534 \\
45 & 15.7 & 510 \\
50 & 13.5 & 506 \\
\hline
\end{tabular}

Table 2 shows the same results for a linear variation in the form of $q^{\prime}(t)=m t$. 
Table 2. Linear heat flux exposure.

\begin{tabular}{ccc}
\hline$m\left[\mathrm{~kW} / \mathrm{m}^{2} \mathbf{s}\right]$ & $t_{\text {ign }}[\mathrm{s}]$ & $E_{c r}\left[\mathrm{~kJ} / \mathrm{m}^{2}\right]$ \\
\hline 0.1 & 231.0 & 562 \\
0.5 & 66.9 & 439 \\
1 & 42.2 & 441 \\
5 & 16.1 & 462 \\
10 & 10.9 & 442 \\
\hline
\end{tabular}

Table 3 presents the results for a quadratic heat flux exposure law similar to the proposal of Eurocode 1 [47]: $q^{\prime}(t)=1000\left(\frac{t}{t_{\text {alpha }}}\right)^{2}$.

Table 3. Quadratic heat flux exposure.

\begin{tabular}{ccc}
\hline$t_{\text {alpha }}[\mathbf{s}]$ & $\boldsymbol{t}_{\text {ign }}[\mathbf{s}]$ & $\boldsymbol{E}_{c r}\left[\mathbf{k J} / \mathbf{m}^{2}\right]$ \\
\hline 150 & 37.0 & 370 \\
300 & 62.8 & 365 \\
500 & 94.2 & 424 \\
600 & 108.9 & 402 \\
\hline
\end{tabular}

Values of the critical energy computed on the base of a critical heat flux of $12.5 \mathrm{~kW} / \mathrm{m}^{2}$ ranged from 350 to $600 \mathrm{~kJ} / \mathrm{m}^{2}$. The value of $400 \mathrm{~kJ} / \mathrm{m}^{2}$ was implemented in the code GoZone, considering this value closer to critical energies obtained with a "quadratic" heat flux exposure Table 2, assumed to better represent a growing fire. Moreover, it can be seen that the time of ignition does not vary significantly if a value of $600 \mathrm{~kJ} / \mathrm{m}^{2}$ is used (Figure 3).

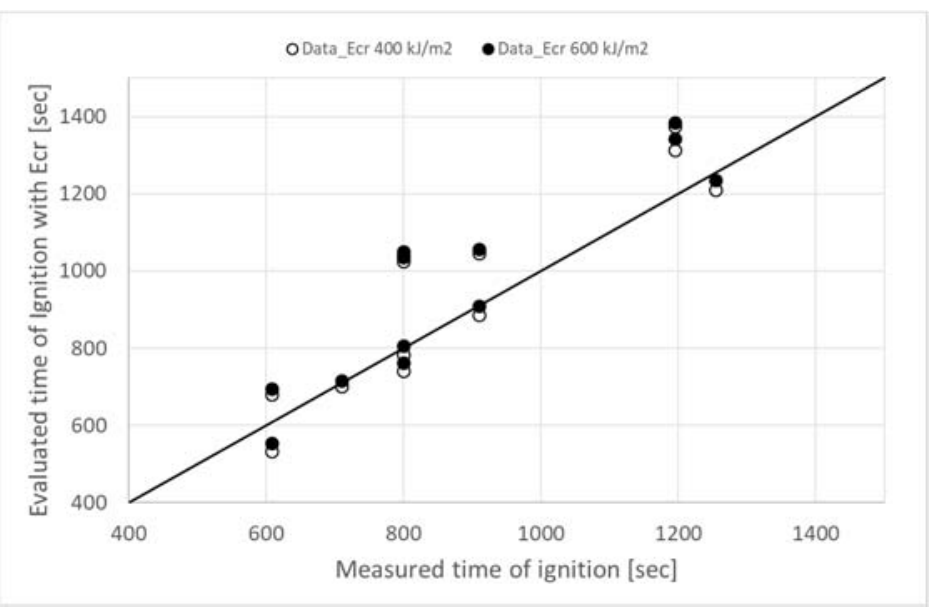

Figure 3. Critical energy comparison to obtain the evaluated time of ignition against the fire test data.

\subsection{Comparison against Fire Test}

A series of natural fire tests have been performed at Liege University in the framework of the European TRAFIR project. Incident heat flux history was measured at different locations from the centre of the fire through vertical and horizontal thermos-plate flux meters [44]. The proposed ignition strategy was tested by comparing the time of ignition evaluated using the recorded heat fluxes with the time of ignition observed during the test. Table 4 shows the results in terms of time of ignition observed in the test, time of ignition evaluated by the model using a critical energy of $400 \mathrm{~kJ} / \mathrm{m}^{2}$, and the error between the model and the tests. 
Table 4. Ignition strategy tested on test series LA.

\begin{tabular}{cccccc}
\hline Test ID & $\begin{array}{c}\text { Distance from } \\
\text { the Origin [m] }\end{array}$ & $\begin{array}{c}\text { Device } \\
\text { Orientation }\end{array}$ & $\boldsymbol{t}_{\text {ign,test }}[\mathbf{s}]$ & $\boldsymbol{t}_{\text {ign,model }}$ [s] & Error [s] \\
\hline LA1v1 & 0.5 & $\mathrm{~V}$ & 741 & 800 & 59 \\
LA1h1 & 0.5 & $\mathrm{H}$ & 1024 & 800 & -224 \\
LA1v2 & 0.5 & $\mathrm{~V}$ & 784 & 800 & 16 \\
LA1h2 & 0.5 & $\mathrm{H}$ & 1039 & 800 & -239 \\
LA1v3 & 0.95 & $\mathrm{~V}$ & 1210 & 1254 & 44 \\
LA2v1 & 0.5 & $\mathrm{~V}$ & 886 & 910 & 24 \\
LA2h1 & 0.5 & $\mathrm{H}$ & 1045 & 910 & -135 \\
LA3v1 & 0.5 & $\mathrm{~V}$ & 1312 & 1195 & -117 \\
LA3h1 & 0.5 & $\mathrm{H}$ & 1373 & 1195 & -178 \\
LA4v1 & 0.5 & $\mathrm{~V}$ & 533 & 608 & 75 \\
LA4h1 & 0.5 & $\mathrm{H}$ & 680 & 608 & -72 \\
LA4v1 & 0.95 & $\mathrm{~V}$ & 701 & 710 & 9 \\
\hline
\end{tabular}

Figure 3 shows the value computed by the model for a critical energy of $400 \mathrm{~kJ} / \mathrm{m}^{2}$ and $600 \mathrm{~kJ} / \mathrm{m}^{2}$ as a function of the observed time of ignition, showing a low dependency of the result of the model on this parameter. It can be observed that the times of ignition were significantly longer than those mentioned in Tables 1-3. This is due to the fact that in these fire propagation tests, it took a significant amount of time for the fire to approach the points of measurements, which means that the received flux was below the critical heat flux until then.

\section{Radiation toward the Cells}

This section describes the models for computing the heat flux received by each cell, essentially by radiation [48] from the hot smoke or from the fire source, in order to apply the ignition strategy described in Section 3.

\subsection{Radiation from the Smoke Layer}

Radiation from the smoke layer was evaluated considering the smoke layer as an isothermal surface with temperature and elevation provided by the zone model (OZone) [49]. Absorption of radiation by air below the smoke layer is considered as negligible [50].

The flux received by a fuel cell $j$ from a smoke cell $i$ is evaluated accounting for the view factor between the two cells [47] and considering a smoke emissivity coefficient $\varepsilon_{f}$ equal to 1.

$$
q_{i-j}^{\prime}=\varnothing_{i, j} T_{i}^{4} \varepsilon_{f} \sigma\left[\frac{\mathrm{W}}{\mathrm{m}^{2}}\right]
$$

The contributions from all smoke cells that are visible by the fuel cell are summed up to compute the total flux received by the fuel cell.

\subsection{Radiation from the Flames}

The semi-empirical model known as the point source model (PSM) [51] was used here to compute the radiation from each burning cell to the fuel cells. PSM assumes the fire to radiate isotropically from a point " $\mathrm{P}$ " at the centre of the flame located at half of the flame length (Figure 4).

The angle $\theta$ between the normal of the receiving surface and the line of sight (target to point source) allows for considering the orientation of the receiving target with respect to the point source. The incident radiant heat flux on the target surface is evaluated according to Equation (3), where $R H R(t)$ is the fire power as a function of time and $\chi_{r}$ is the radiative fraction coefficient set as 0.3 [52].

$$
q^{\prime}(t)=\frac{\chi_{r} R H R(t)}{4 \pi R(t)^{2}} \cos \theta(t)\left[\frac{\mathrm{W}}{\mathrm{m}^{2}}\right]
$$




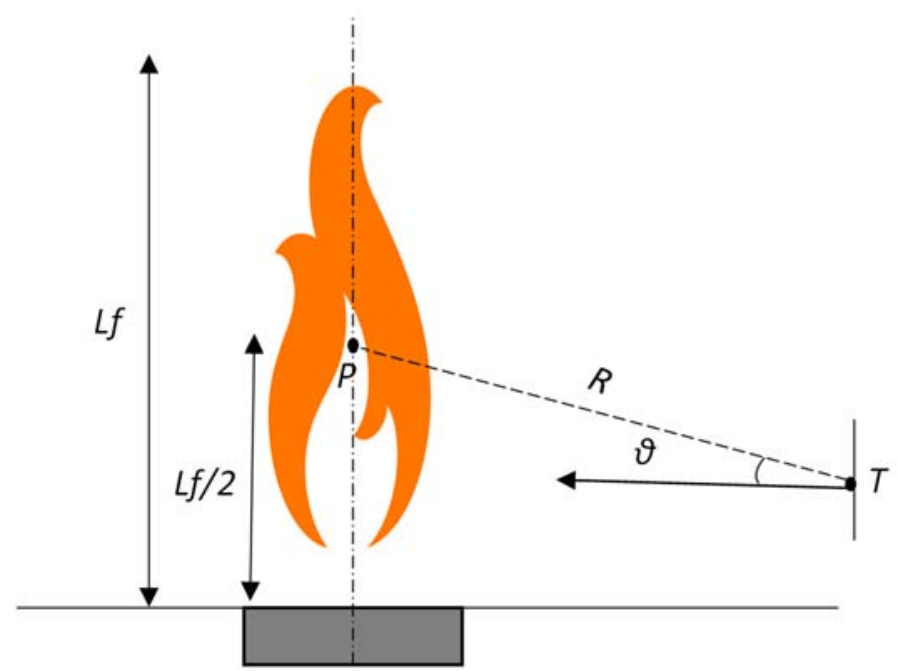

Figure 4. Point source model.

Opinions on PSM are controversial in the literature. Casal stated that PSM overestimates the intensity of the thermal radiation for a target close to the fire [53]. Drysdale, in contrast, wrote that PSM underestimates thermal radiation for close targets [52]. Fleury, after having tested several semi-empirical models for the incident heat flux evaluation toward a wide range of target orientations and fire powers, concluded that PSM was the most accurate model among the ones analysed in his work [54]. PSM was tested here with respect to real experimental tests on localised pool fires and to CFD simulations.

Figure 5 shows a comparison between the PSM and 18 different pool fire tests conducted within the framework of the RFCS project LOCAFI [13]. The flux measurements during the tests were taken at a fixed distance of approximately $3 \mathrm{~m}$ from the centre of the fire and each test had a different steady state fire power created by different diameters.

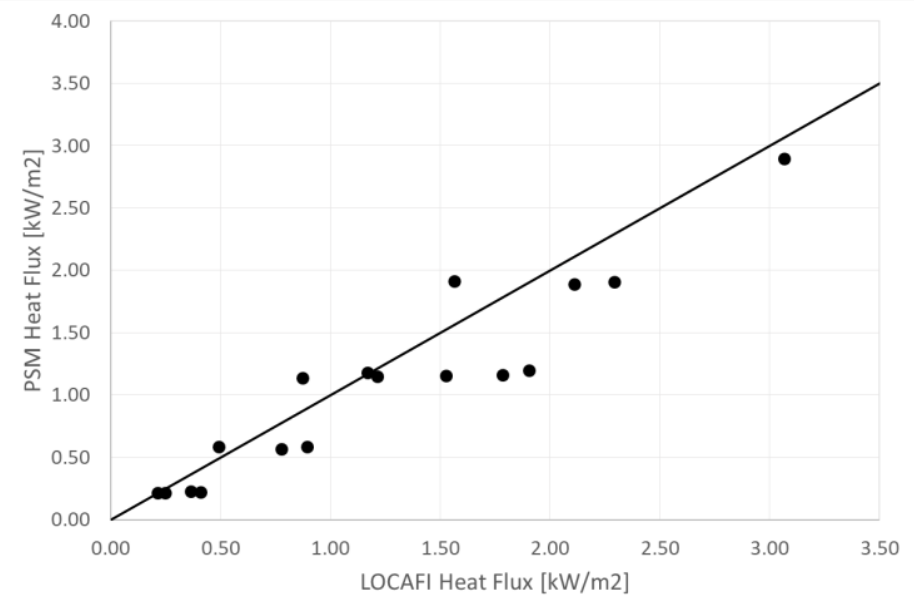

Figure 5. PSM compared with 18 pool fires; data from the LOCAFI project.

Gas burners of different constant powers $(200,500,750,1000 \mathrm{~kW})$ have been modelled in FDS [15]. The incident radiative heat flux has been computed at $1 \mathrm{~m}, 2 \mathrm{~m}$, and $3 \mathrm{~m}$ from the fire centre by varying the target orientation. Figure 6 shows the results for vertical orientation facing the fire source, represented with black dots, whereas the white filled dots are for the horizontal orientation. 


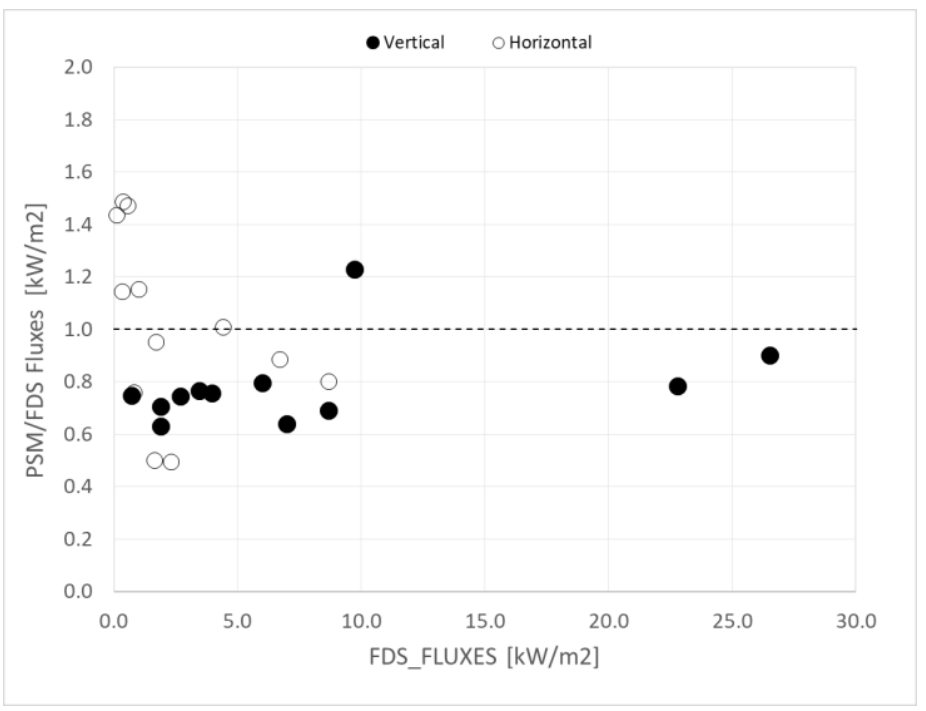

Figure 6. Comparison of PSM and FDS measured heat fluxes on the vertical target surface and horizontal target surface.

Figures 5 and 6 tend to confirm the conclusion drawn by Fleury [54] that PSM is an appropriate tool for the radiative heat flux estimation.

Fire is started by choosing a fire origin cell as most fires start as localised. In several analytical TFM, the fire is assumed to start as a line perpendicular to the path that the fire will follow, with the line as long as the width of the compartment. In this model, the fire is started by choosing a fire origin cell according to the fact that, except in the case of arson or explosion, most fires start as a local fire. The RHR of a burning cell is defined according to the indication provided by Eurocode 1-2 [47]. Assuming a fuel controlled fire, there are three main fire stages for the burning cells: (1) an initial growing phase, depending on the fire growth rate assigned; (2) a stationary regime in which the cell is burning entirely and the RHR is a function of the area of the fire and the $R H R_{f}$; and (3) a linear descending phase starting when $70 \%$ of the fire load is consumed. In this context, if the fire propagates, the sum of $R H R(t)$ produced by each cell is the total fire power and the total fire area is evaluated the same way by summing the fire area of each burning cell.

The PSM model cannot be used here with a representation of the whole fire engulfed area by a single point. This is due to the complex shape that the fire can take in a plan view depending on the fire origin and considering that the model should be applicable in compartments of any shape. In compartments with a concave plan view, the fact that a single point is visible for a cell or not would result in dichotomist yes/no possibilities, whereas a cell may see part of the fire source but not all of it. The PSM model has to be applied cell by cell. This yields the question of the evaluation of the flame length for each burning cell and of the mesh sensitivity of the discretised model.

Heskestad formulation (Equation (4)) is widely adopted to evaluate the flame length of localised fires $[47,55]$.

$$
L_{f}=-1.02 D+0.0148 Q^{\frac{2}{5}}
$$

Flame length in Equation (4) relates to the fire central axis for a given fire diameter $D$ and power $Q$. It is not appropriate for evaluating the flame length of individual cells that form an otherwise greater fire because it would amount to considering a large number of fires with a small diameter located side by side. An approach inspired by a non-local variable concept is proposed here. The non-local variable concept is used, for example, as a solution for failure processes characterized by strain localisation into shear bands where related classical continuum theories reach the limits of application [56].

In general, all non-local variable methods rely on a characteristic length that governs the size of the region of influence on the point that is being considered. A characteristic 
length $L_{C H}$ of $2 \mathrm{~m}$ was found appropriate here through calibration of the model presented hereafter with circular shaped fires with a radius varying from 1 to $5 \mathrm{~m}$ and rate of heat release densities of 250 and $500 \mathrm{~kW} / \mathrm{m}^{2}$.

An equivalent fire area was first evaluated for each burning cell $i$ with central coordinates $\left(x_{i}, y_{i}\right)$ using Equation (5) where the surface integration was conducted on the whole burning domain.

$$
\begin{gathered}
\Omega_{e q, i}(x, y)=\iint_{x, y} \exp \left(-d(x, y) / L_{C H}\right) d x d y \\
d(x, y)=\sqrt{\left(x_{i}-x\right)^{2}+\left(y_{i}-y\right)^{2}}
\end{gathered}
$$

An associated equivalent diameter was computed from the equivalent fire area (see Equation (6)).

$$
D_{\text {eq }, i}=2\left(\Omega_{\text {eq }, i} / \pi\right)^{0.5}
$$

The flame length for the cell is then computed using Equation (7).

$$
L_{f, e q, i}=-1.02 D_{e q, i}+0.0148 Q_{e q, i}^{\frac{2}{5}}\left(D_{e q, i}\right)
$$

where $Q_{e q, i}$ is computed by the product of the rate of heat release density by the equivalent area of the cell.

Figure 7 shows the results of the non-local variable methodology in terms of the shape of the global fire as reconstructed from the length of the flame in each cell, for two different shapes of the fire area and two very different mesh refinements.

A comparison between the flame length evaluated with this methodology and the one provided by Heskestad can be conducted within the range of applicability of the Heskestad formulation, thus in the central axis of a circular fire area limited to a maximum radius of $5 \mathrm{~m}$. Several circular fires of radius ranging from $2 \mathrm{~m}$ to $5 \mathrm{~m}$ were discretised. In Figure 8, the mesh represents the evaluated flame length in the centre of each discretised cell and in the central axe of the fire area according to the Heskestad equation (red asterisk) for a given radius and constant $R H R_{f}$ of $250 \mathrm{~kW} / \mathrm{m}^{2}$.

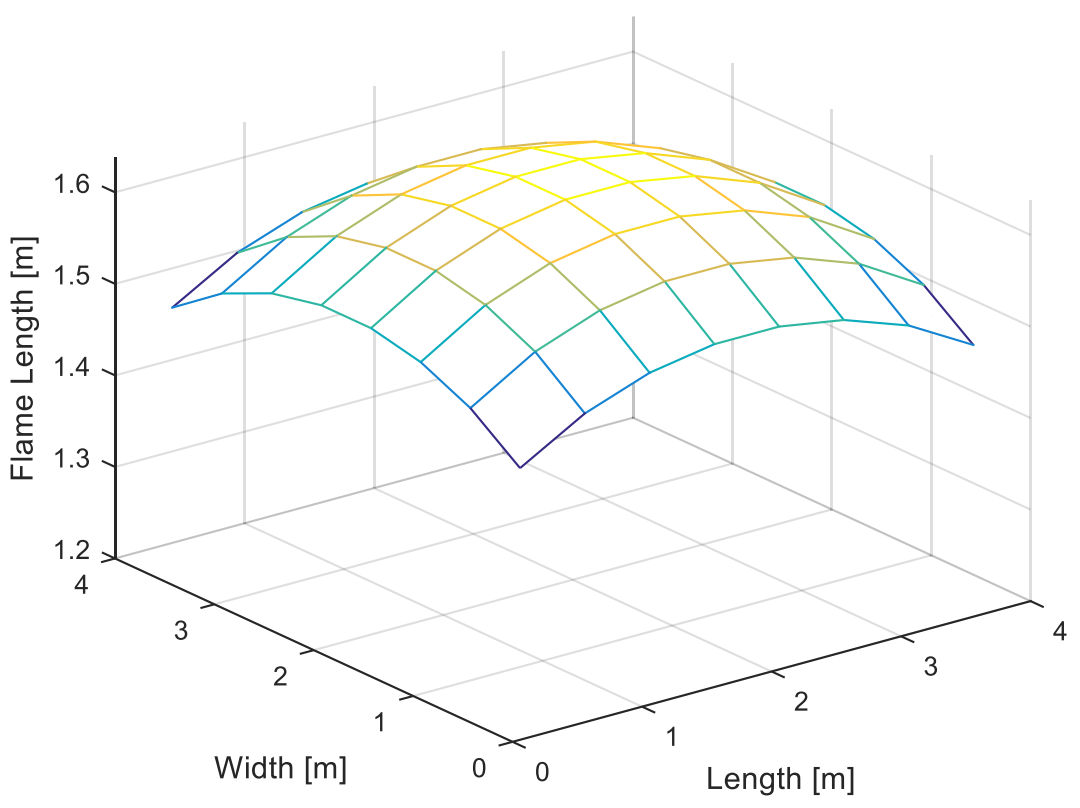

(a)

Figure 7. Cont. 


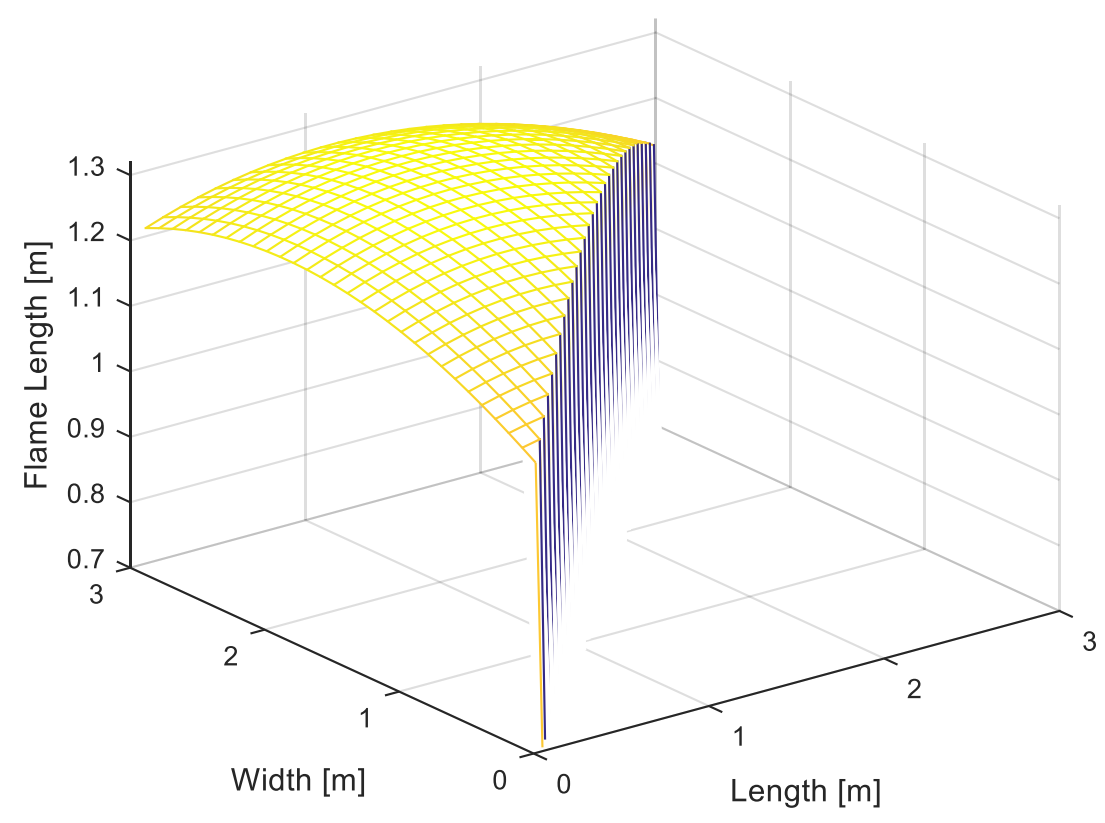

(b)

Figure 7. Reconstructed global flame shape: (a) square shape; (b) triangular shape.

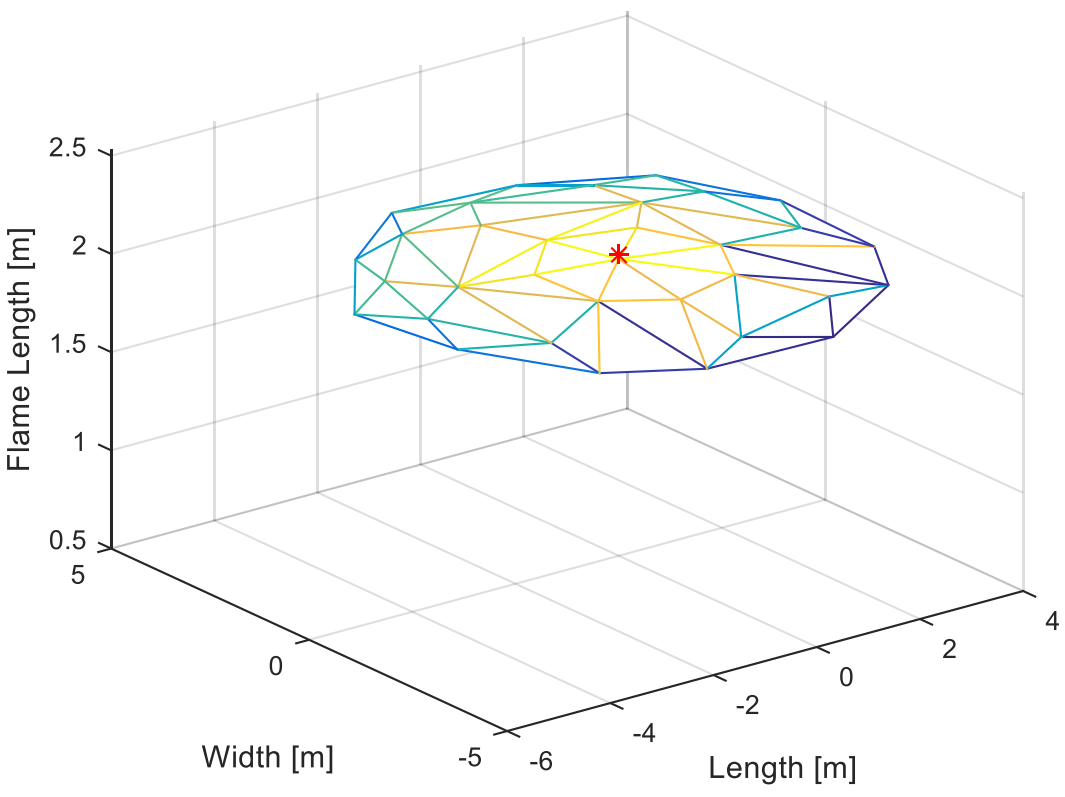

Figure 8. Flame length shape for a circular fire area with a radius of $5 \mathrm{~m}$.

In Figure 9a the flame length at the centre of the circular area from the non-local variable method was plotted as a function of the number of discretised elements; this showed that the result was not mesh sensitive. In Figure 9b, a comparison between the analytical solution at the centre of the circular area and the non-local variable method showed an error between 6 and 13\%, which was also not mesh sensitive.

In Figure 10, the flame length at the centre was evaluated for different square fire areas, varying the cell size discretised with quadrilateral structured elements. The behaviour of the function was in line with that observed for a circular shape area in Figure 9a, appearing to be quasi mesh insensitive. 
The flame temperature can be evaluated for each cell according to Equation (9) as suggested in Annex C of EN1991-1-2 [47].

$$
\begin{gathered}
z_{0, e q, i}=-1.02 D_{e q, i}+0.00524 Q_{e q, i}^{\frac{2}{5}} \\
T_{f e q, i}(z)=20+0.25 Q_{c, e q, i}^{\frac{2}{3}}\left(z-z_{0, e q, i}\right)^{-\frac{5}{3}}
\end{gathered}
$$

where $z$ is taken as half the flame length according to the concept of PSM.

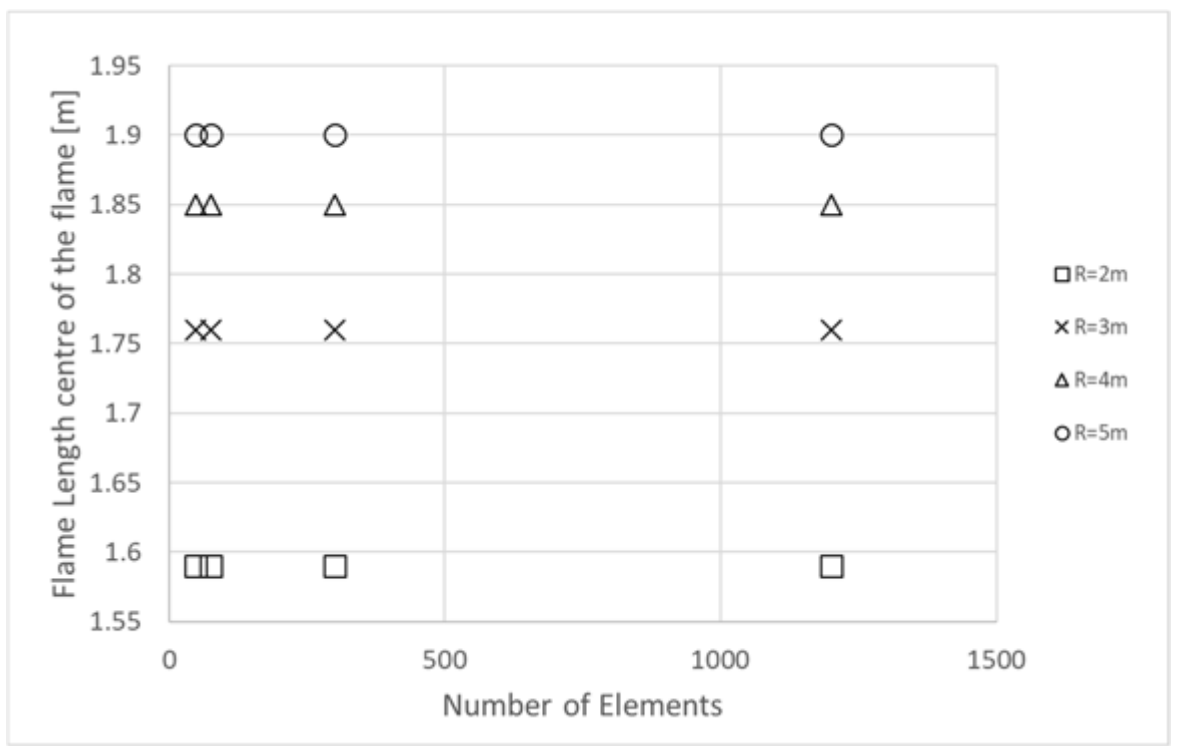

(a)

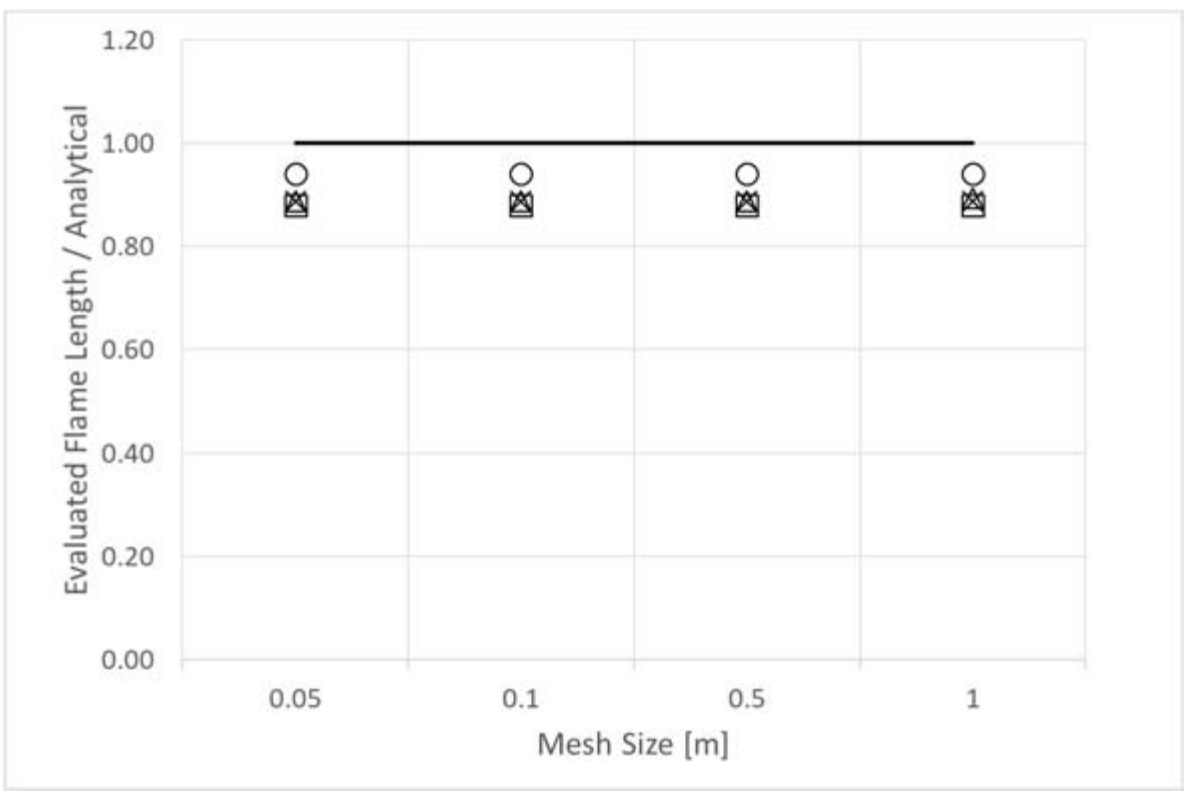

(b)

Figure 9. Flame length: (a) non-local variable method approach varying the number of elements $(48,75,300,1200)$ and fire radius; (b) comparison with the Heskestad equation at the centre of the fire. 


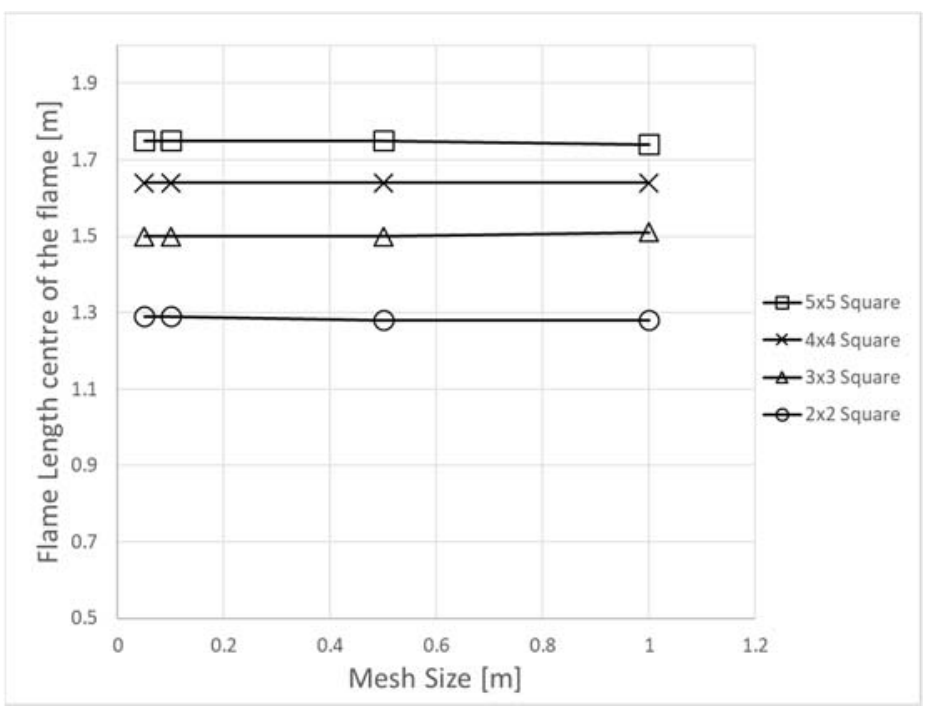

Figure 10. Flame length evaluated at the centre of the flame for several fire areas and discretised cells.

As has been conducted for the evaluation of the flame length, the temperature of the flame along the central axis of a circular fire was computed and is shown in Figure 11, first considering the fire as a whole (full line), and then considering the temperature evolution in the central cell of the discretised fire (dotted line).

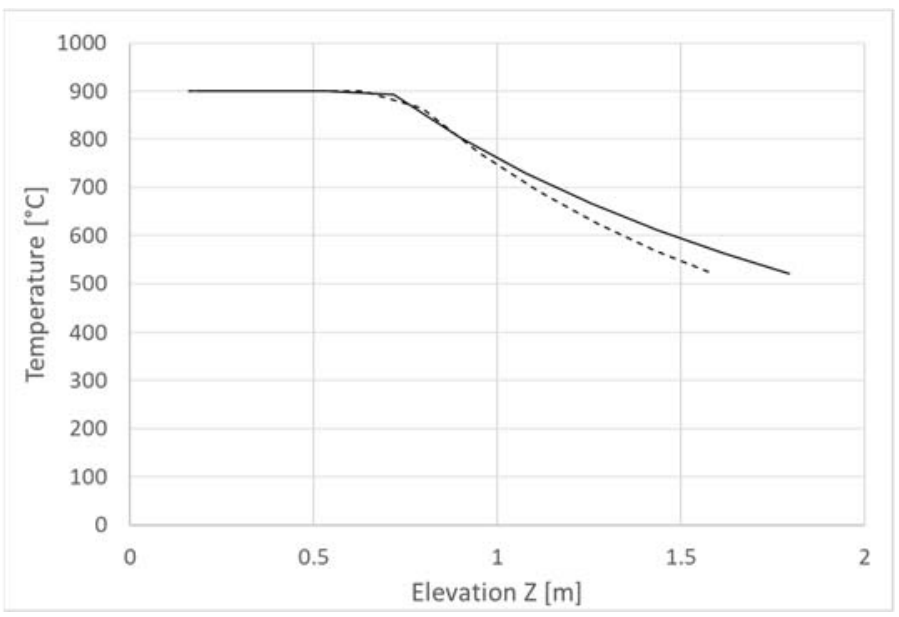

Figure 11. Central axis temperature comparison between Eurocode 1 and the non-local variable method for a fire radius of $2 \mathrm{~m}$.

\section{Fuel Control Situations}

The rate of heat release (RHR) of each burning cell is pre-defined according to the recommendations of Eurocode 1 part 1-2 [47] for a fuel controlled fire, with three main stages: (1) an initial growing phase, depending on the assigned fire growth rate; (2) a stationary regime during which the RHR is equal to the product between the area of the cell and the value of given rate of heat release density; and (3) a linear descending phase starting when $70 \%$ of the fire load of the cell is consumed. When the fire propagates, the sum of RHR(t) produced by all cells makes the total fire power in the compartment used by the zone model. The advantage in defining the fire power evolution according to the recommendations of EN1991-1-2 is in having input parameters that are relatively easy to understand, familiar to practitioners (RHR density, fuel load, and fire growth rate). A $20 \times 20 \mathrm{~m}^{2}$ well ventilated compartment with the ceiling at $2.7 \mathrm{~m}$ was taken to check the growing phase evolution in terms of the rate of heat released evaluated by GoZone through a comparison with the analytical solution of EN1991-1-2. Table 5 shows the three different 
compartment typologies that were tested with regard to the fuel load density, rate of heat release density, and fire growth rate described in Tables E.4 and E.5 of EN1991-1-2.

Table 5. Investigated compartment typologies.

\begin{tabular}{cccc}
\hline & $\boldsymbol{t}_{\text {alpha }}[\mathrm{s}]$ & $\boldsymbol{R H R}_{\boldsymbol{f}}\left[\mathrm{kW} / \mathbf{m}^{2}\right]$ & $\boldsymbol{q}_{f, d}\left[\mathrm{MJ} / \mathbf{m}^{2}\right]$ \\
\hline Shopping centre & 150 & 250 & 730 \\
Office & 300 & 250 & 511 \\
Transport (public space) & 600 & 250 & 122 \\
\hline
\end{tabular}

The fire origin was set in the centre of the compartment and the comparison was made up to the moment when the smoke layer was predominantly influencing the fire dynamics or when the fire completely engulfed the compartment. This is because the equation of Eurocode 1 does not stand when any of these two criteria is met.

Figures 12 and 13 show the evolution of the power released during the growing phase of a fast and a medium fire. Outcomes provided by GoZone seem to be reasonably in line with the analytical solution.

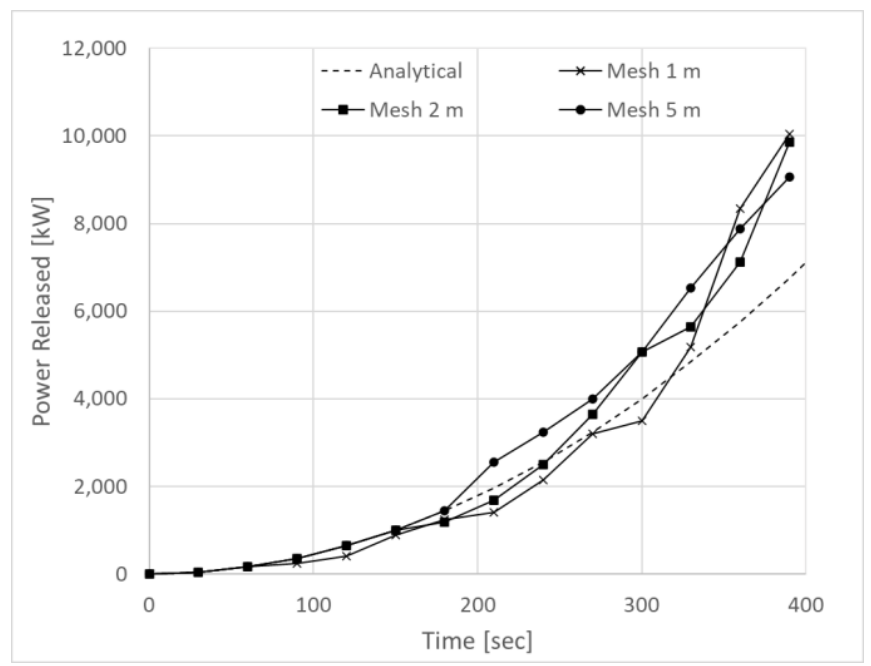

(a)

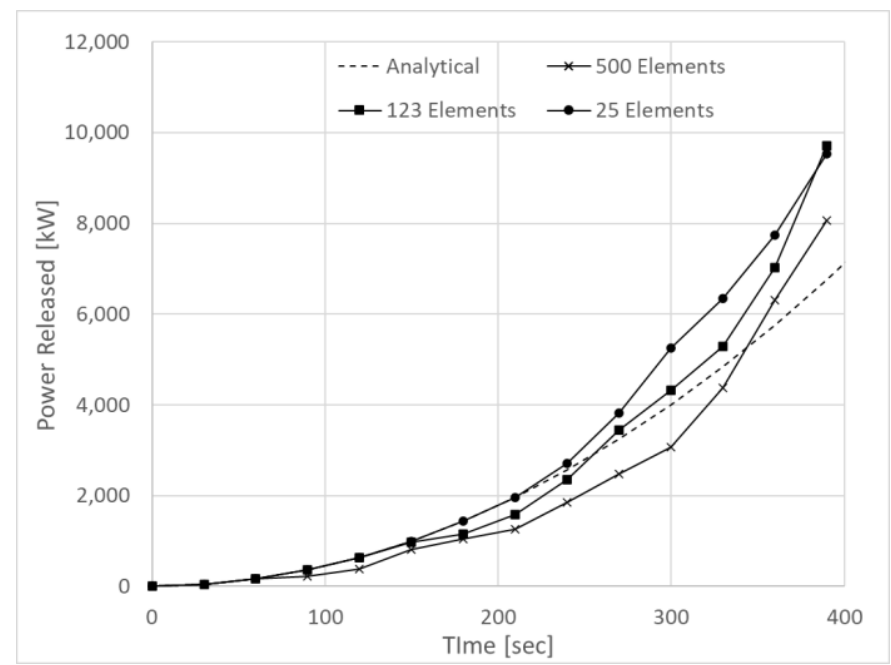

(b)

Figure 12. Evolution of the power released in a shopping centre: (a) Structured quadrilateral mesh; (b) Unstructured quadrilateral mesh. 


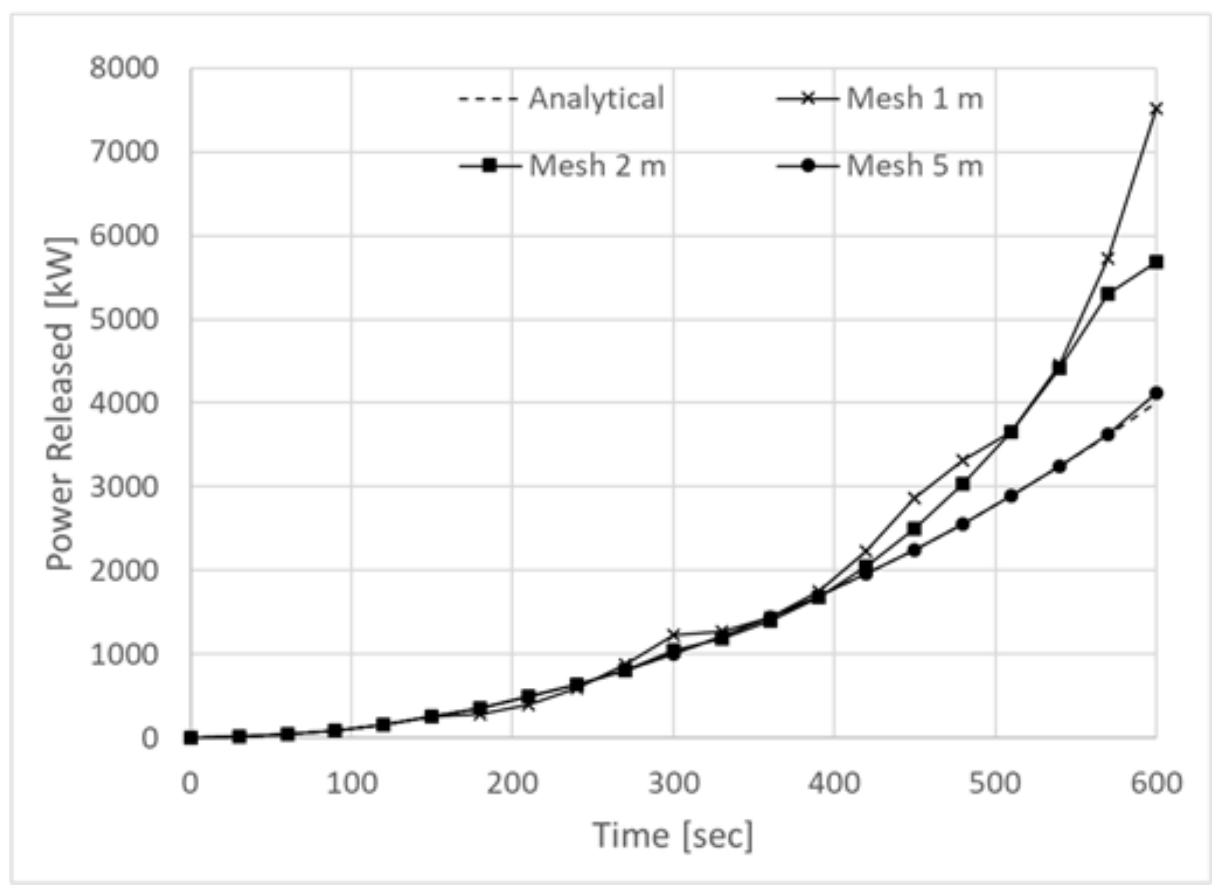

(a)

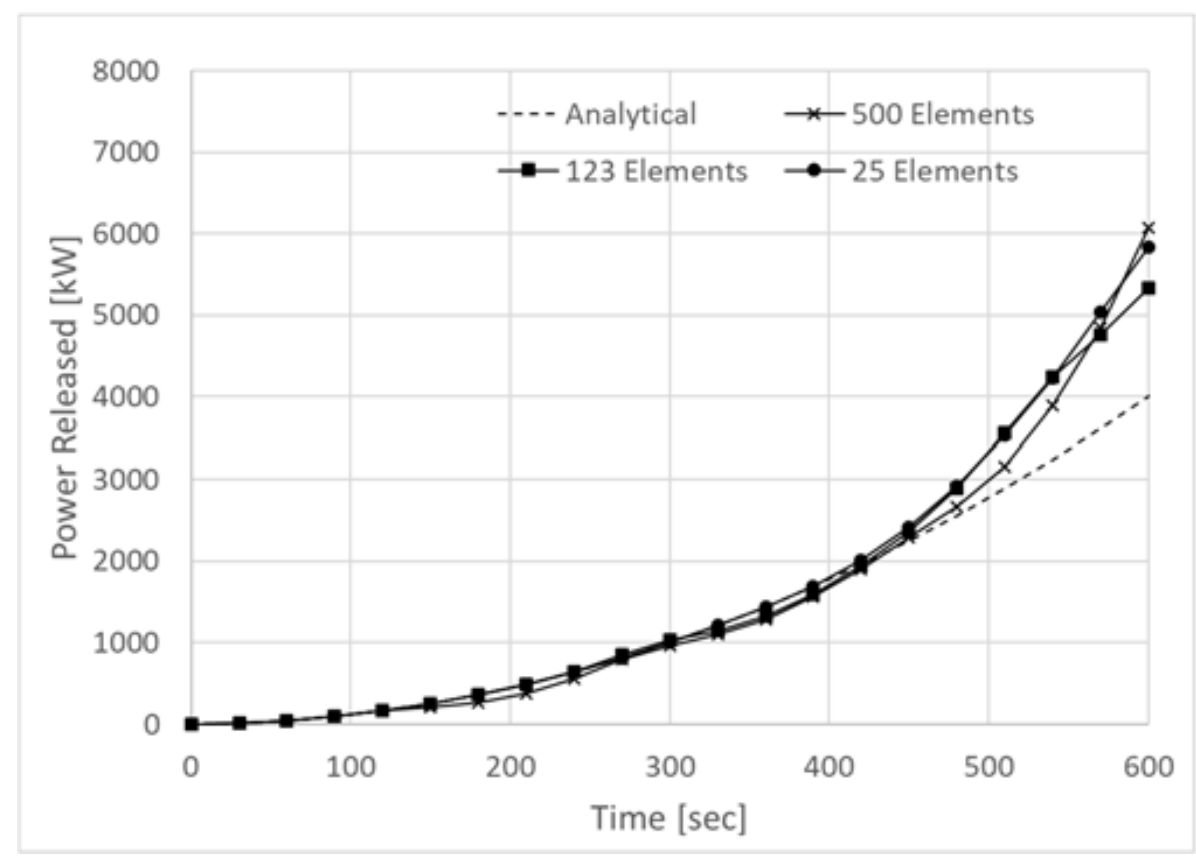

(b)

Figure 13. Evolution of the power released in an office building: (a) Structured quadrilateral mesh; (b) Unstructured quadrilateral mesh.

Figure 14 shows the fire propagation predicted by GoZone, which is representative of a medium fire from the time of first ignition to a moment just before the flashover. Since fast and medium fire development were similar in terms of the shape of the fire evolution, only one case is shown and is considered to be representative of the two.

Figure 15 shows the evolution of the power for a slow fire scenario. Although the general trend of the numerical model is still the one of the analytical solution, a different behaviour could be observed compared to Figures 13 and 14, where the power released did not increase monotonously, especially for cruder meshes. 


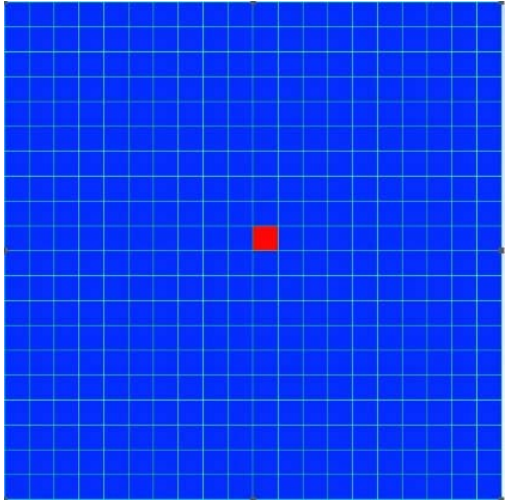

(a)

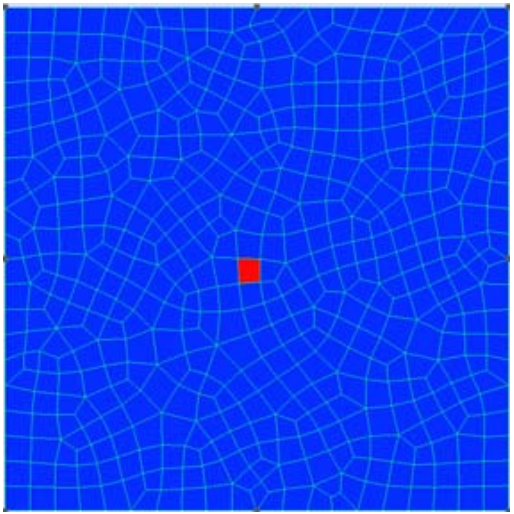

(d)

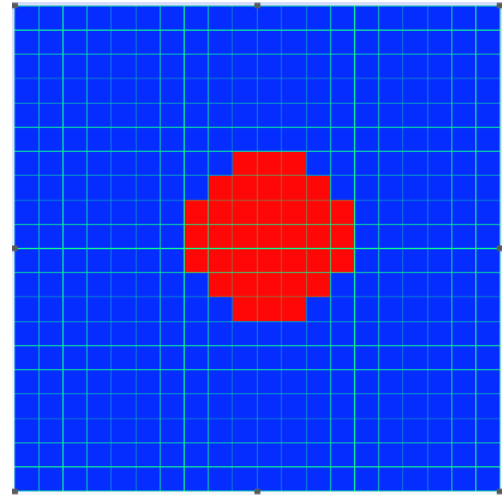

(b)

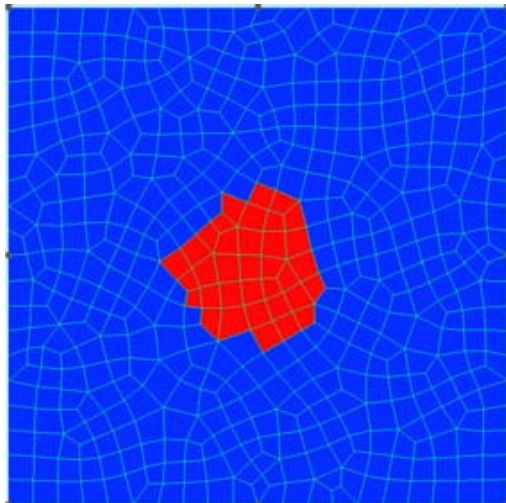

(e)

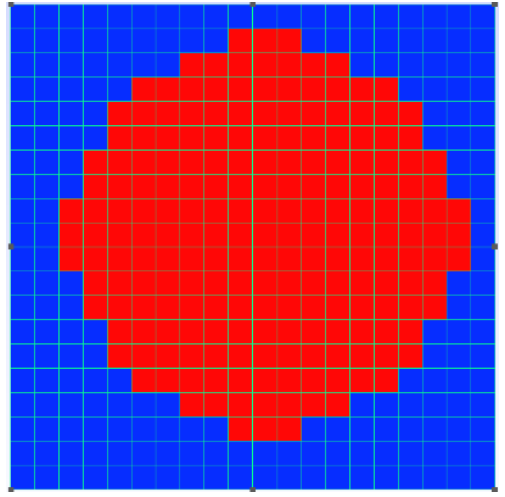

(c)

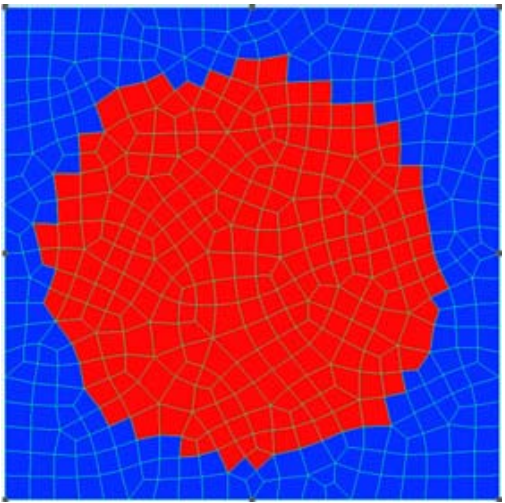

(f)

Figure 14. Fire evolution from ignition to a moment before flashover representative of medium and fast fire growth scenarios. $(\mathbf{a}-\mathbf{c})$ Evolution with a structured mesh; $(\mathbf{d}-\mathbf{f})$ Evolution with unstructured mesh.

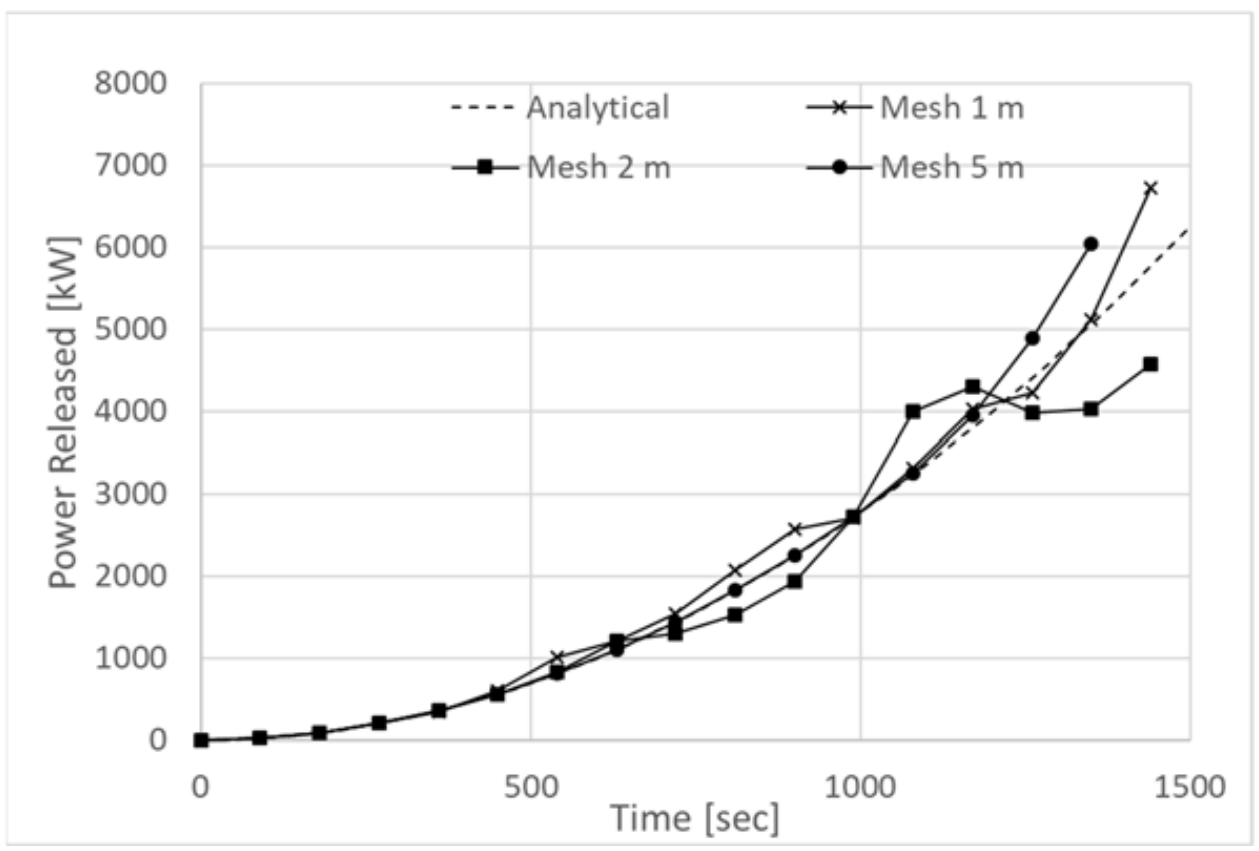

(a)

Figure 15. Cont. 


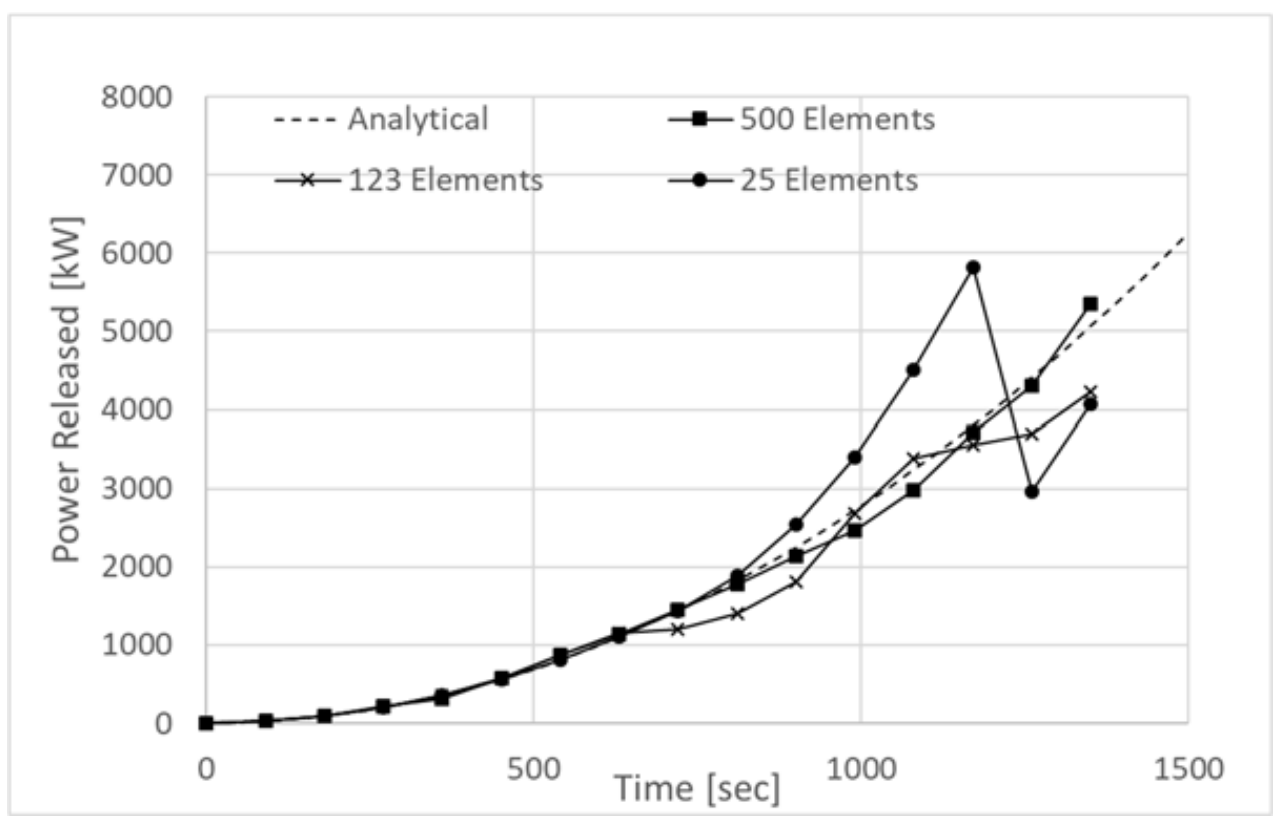

(b)

Figure 15. Evolution of power released in public space: (a) Structured quadrilateral mesh; (b) Unstructured quadrilateral mesh.

This is due to the fact that, in this case, a slow fire produces some kind of radial travelling fire, as can be seen in Figure 16. In this figure, red cells are in the increasing or steady state period of combustion; pink cells are in the descending phase; and black cells are completely burnt. Due to the discretised nature of the floor in cells of finite sizes and to the regular geometry, it may occur that a significant amount of cells enter in the descending branch or are completely consumed, whereas for a certain amount of time, no new cell is ignited. This phenomenon is amplified by the larger size of the meshes and by the double symmetry of the problem, which makes groups of several cells, thus changing their behaviour at the same time.
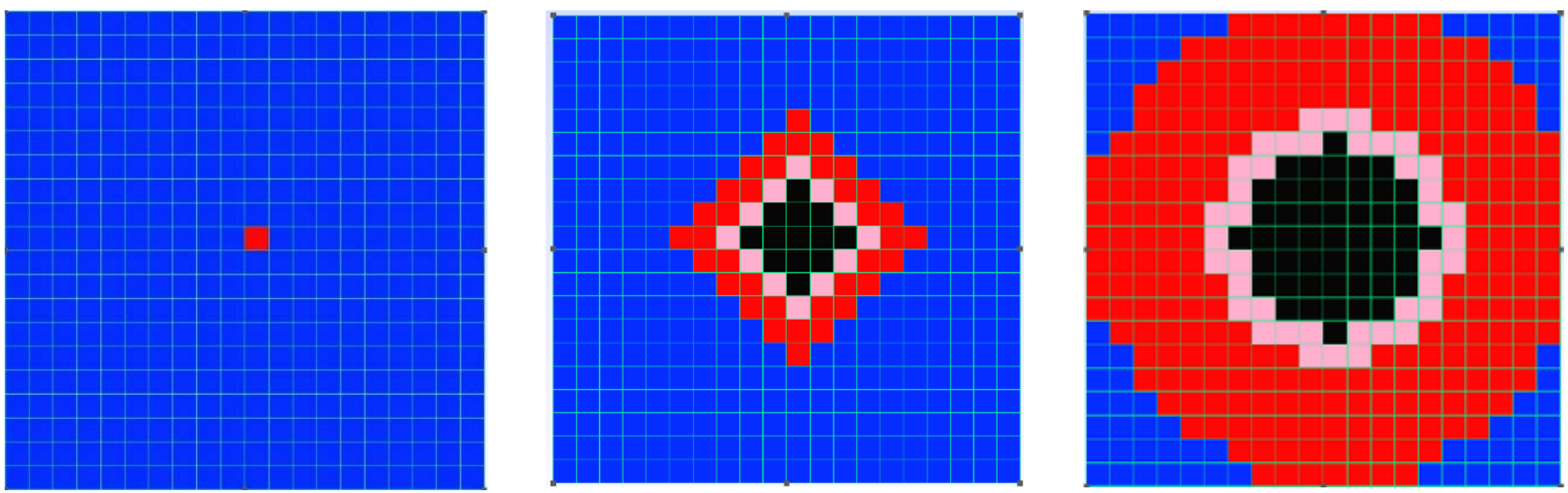

Figure 16. Fire evolution from left to right for structured mesh representative for a slow fire growth rate scenario.

Comparison of Figures 12, 13 and 15 showed that the simple adaptation of the parameter $t_{\text {alpha }}$ in each cell led to an ignition strategy that globally reproduced the desired propagation velocity depending on the occupation of the compartment, bypassing the necessity to define the type and proportion of the different materials present in the compartment, each with its specific ignition propensity. 


\section{Strategy for Air Control}

The mass of oxygen in the compartment was considered as $23 \%$ of the total mass of air present in the compartment. The oxygen fraction in the air was equal to $21 \%$, however, OZone has been extensively validated with $23 \%$, so this value was taken for sake of consistency [57]. The zone model considers the oxygen mass balance equation according to Equation (10), where a stoichiometric combustion factor of wood equal to 1.27 was considered for the combustion process [52].

$$
m_{o x}{ }^{\prime}=m_{o x, i n}{ }^{\prime}+m_{o x, o u t}{ }^{\prime}-1.27 m_{f i}{ }^{\prime}
$$

The oxygen distribution in the compartment is assumed to be uniform according to the hypothesis of a well steered reactor and the fire is assumed to be in a fuel controlled regime as long as the oxygen content obtained by time integration of Equation (10) is positive. When the oxygen content drops to zero, the strategy in air-controlled regime is inspired from an extended fire duration concept, in the sense that the pyrolysis rate and, as a consequence, the power released in the compartment are proportional to the mass of oxygen mass entering from the openings in the compartment (Equation (11)).

$$
R H R_{a i r}=\sum_{i}^{n b \text { openings }} m_{f i}{ }^{\prime}(i) H_{c, e}=\frac{m_{o x, i n}{ }^{\prime}(i)}{1.27} H_{c, e}
$$

where $H_{c, e}$ is the effective heat of combustion taken as $14 \mathrm{MJ} / \mathrm{kg}$.

The total power available is distributed to the cells that are closest to the opening's location among those that were burning before the switch to the air-controlled regime. Ignition of new cells and propagation of the fire during the air controlled regime is still possible provided that the critical energy criteria is met in some cells and if the limit in terms of power given by Equation (11) is not exceeded. This will happen typically when either breakage of a new opening is detected (according to the different strategies implemented in the zone model [9]) or if some burning cells enter in the decreasing phase. In this case, the cell among the non-burning cells, which is the closest to an active opening, will ignite or re-ignite first.

\section{Comparison with BST/FSR 1993: Test 2}

The BST/FSR test series performed in 1993, better known as Gordon Cooke's fire tests, consist of nine different compartment fire tests performed in one compartment with varying fuel load, opening size, and ignition methodology [21]. The test compartment was $22.8 \mathrm{~m}$ long, $5.6 \mathrm{~m}$ wide, and $2.75 \mathrm{~m}$ high, with an opening on one short end of the compartment. The fuel was made of wood crib piles uniformly distributed on the whole floor area, ignited at the opposite side with respect to the opening position. The authors consistently observed in the nine tests performed that the fire travelled from the back of the compartment toward the opening, seeking air, then once all the fuel was consumed near the opening region, the fire travelled back again toward the ignition region.

This test series is emblematic because it may be regarded as an early example of what is now termed as "travelling fires", where the position of the burning zones moved and was severely influenced by the ventilation. Recently, Dai et al. [22] tried to model and represent the "BST/FSR Test 2" with FDS [15], obtaining a good agreement with the fire dynamic observed in the test. However, the rate of heat release assigned to each row of crib in the model was extrapolated based on the crib mass loss rate measured during the test and assigned crib by crib according to their position using several ramp functions. The authors thus showed how FDS is able to replicate travelling fire behaviour in under-ventilated condition but were not able to predict its complex behaviour a priori.

GoZone was compared with the BST/FSR test 2 in order to evaluate its ability to predict this particular fire dynamic. For test number 2, Kirby et al. provided the evolution of the temperature distribution in the compartment for three specific crib lines (Figure 17). 
These information were used here to extrapolate the fire dynamics and to compare the test results with the model's outputs.

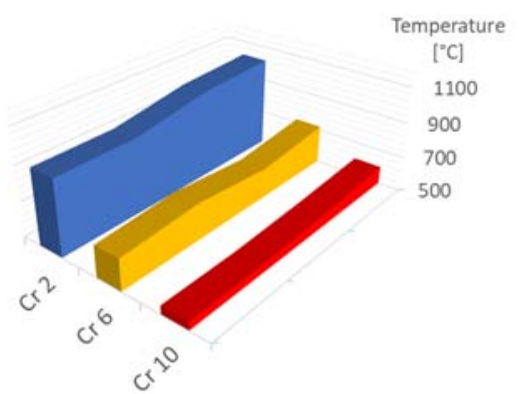

(a)

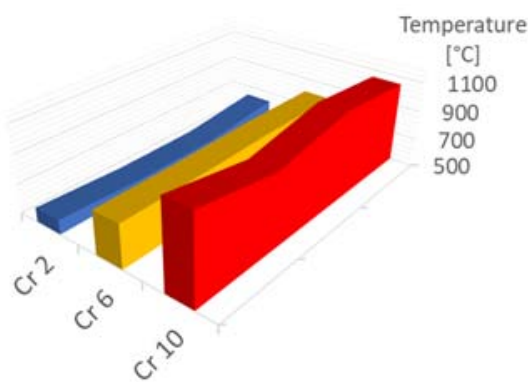

(b)

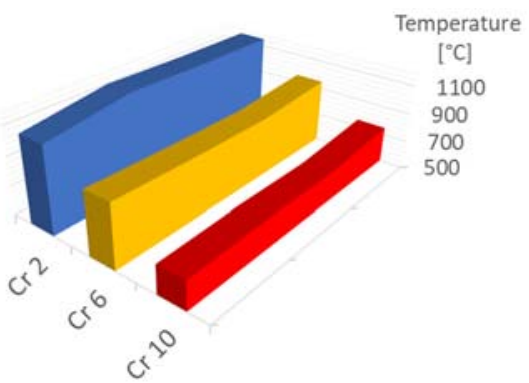

(c)

Figure 17. Temperature distribution on crib lines 2, 6, and 10 at times: (a) $15.5 \mathrm{~min}$, (b) $23 \mathrm{~min}$, (c) $53.5 \mathrm{~min}$.

The compartment was modelled in GoZone with a mesh size of $1 \mathrm{~m}$ and discretised with 205 unstructured quadrilateral cells. Each cell was characterised with the parameters in Table 6.

Table 6. Main inputs for simulation test 2.

\begin{tabular}{ccccc}
\hline $\begin{array}{c}\text { Fuel Load } \\
\left.\text { Density [MJ/m }{ }^{2}\right]\end{array}$ & $\begin{array}{c}\text { Rate of Heat Release } \\
\text { Density }\left[\mathbf{k W} / \mathbf{m}^{2}\right]\end{array}$ & $\begin{array}{c}\text { Fire Growth } \\
\text { Rate }[\mathbf{s}]\end{array}$ & $\begin{array}{c}\text { Critical } \\
\text { Energy }\left[\mathbf{k J} / \mathbf{m}^{2}\right]\end{array}$ & $\begin{array}{c}\text { Critical Heat } \\
\text { Flux }\left[\mathbf{k W} / \mathbf{m}^{2}\right]\end{array}$ \\
\hline 380 & 250 & 300 & 400 & 12.5 \\
\hline
\end{tabular}

The fuel load density is given in Kirby et al. [21]; however, to characterise the fuel cell, GoZone also needs the rate of heat release density and fire growth rate. These input parameters were chosen according to the suggestion provided by Eurocode 1 part 2 where a fuel load density of $380 \mathrm{MJ} / \mathrm{m}^{2}$ can be associated with a Hotel Room compartment according to Table E.4. (Annex E of EN1991-1-2) Therefore, the rate of heat release density and fire growth rate were chosen consistently according to Table E.5 (Annex E of EN1991-1-2). A comparison with the tests was thus made in a situation that is as close as possible to a design situation in which the fire action is not known a priori. Critical energy of ignition and critical heat flux were not tuned for this particular test but taken as determined in Section 3.

Figure 18 shows the results in terms of fire evolution. The fire was ignited on the left hand side and initially propagated slowly toward the opening (Figure 18a), then the increasing temperature in the hot gases and the associated radiation helped the fire to spread faster toward the opening. The compartment at $19 \mathrm{~min}$ was completely engulfed in flames. After a few minutes, a transition to an air-controlled situation due to a lack of oxygen took place. Cells on the opposite side of the opening, depicted in yellow (Figure 18b), cannot burn due to a lack of oxygen. The air entering from the opening feeds the burning cells (red) and the fire travels from the opening to the opposite side (Figure 18c). At $64 \mathrm{~min}$, the fire is completely extinguished.

Comparison between Figures 17 and 18 show that GoZone can predict the complex fire behaviour observed in this specific test in terms of fire position and total duration. The total simulation time on a laptop was $54 \mathrm{~s}$.

Comparisons in terms of evolution of gas temperature among the compartment length just above crib lines 2, 6, and 10 in the centre line of the compartment are shown in Figure 19, as measured during the test, as evaluated by GoZone, and extrapolated from Dai et al. [22] as a result of FDS analysis.

Figure 19a,b shows that the two separate peaks of temperature when the fire travels back and forth can be reproduced by the CFD replication of the test as well as by the GoZone a priori prediction, with the level of maximum temperature better predicted in the 
latter. Both models correctly predicted the maximum temperature in crib line 10, which was close to the opening (see Figure 19c). The cooling down phase was better predicted by GoZone.

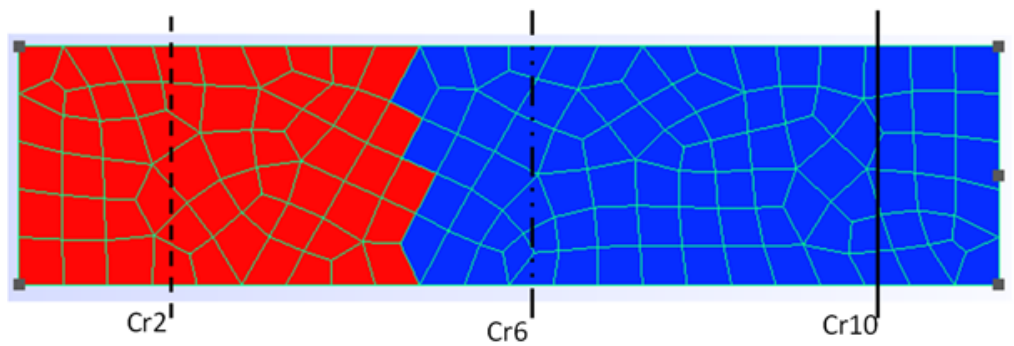

(a)

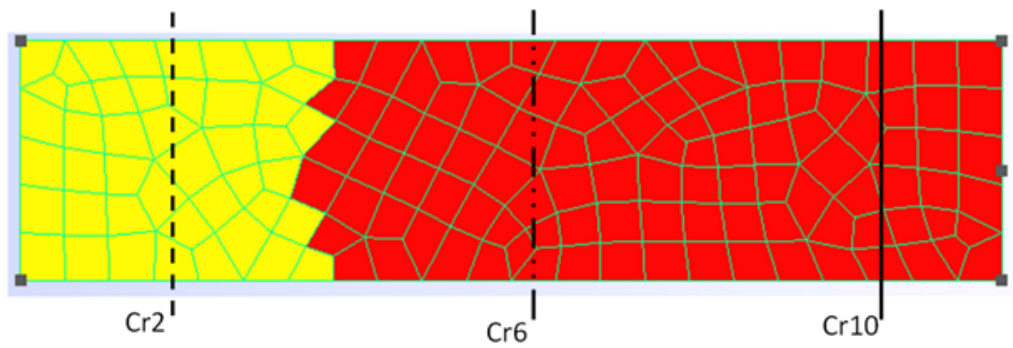

(b)

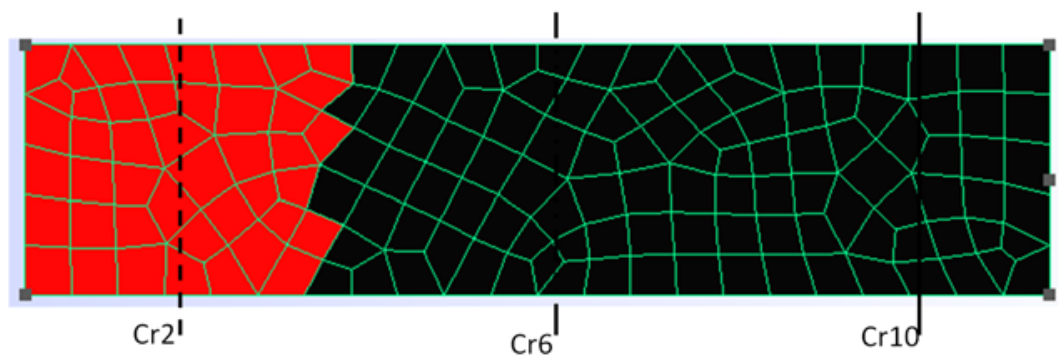

(c)

Figure 18. Fire evolution according to GoZone in BST/FSR test 2: (a) $15 \mathrm{~min}$; (b) $23 \mathrm{~min}$; (c) $53 \mathrm{~min}$.

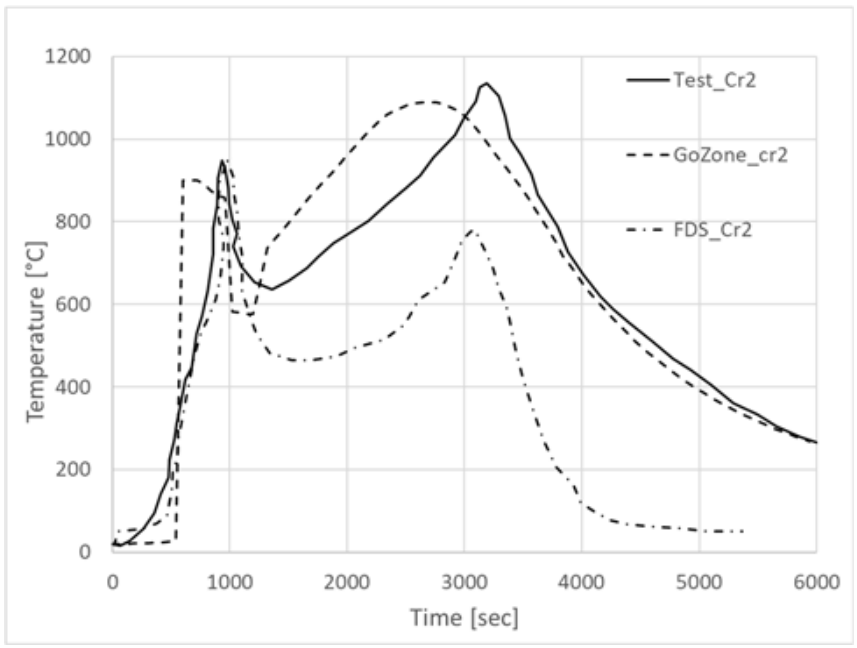

(a)

Figure 19. Cont. 


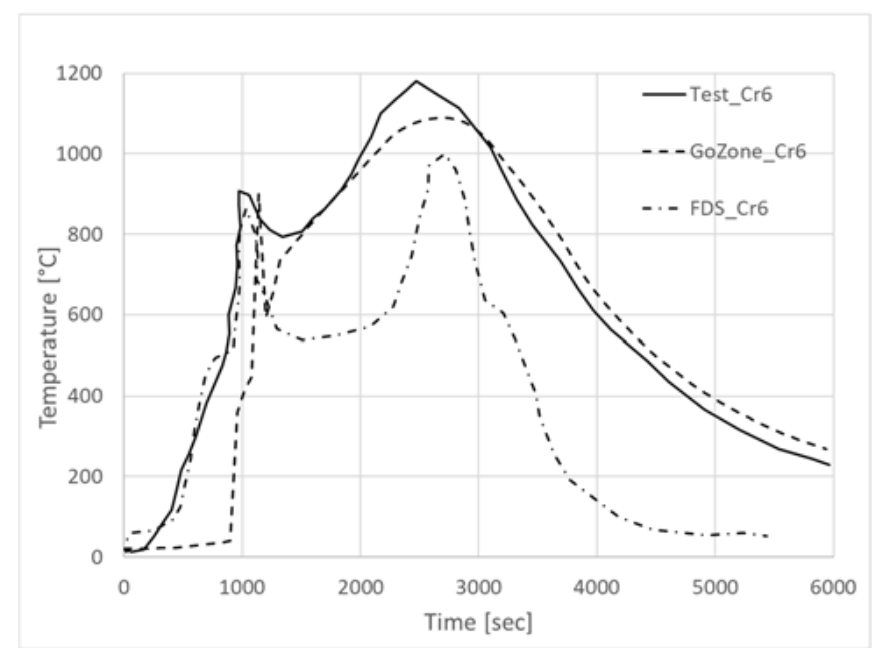

(b)

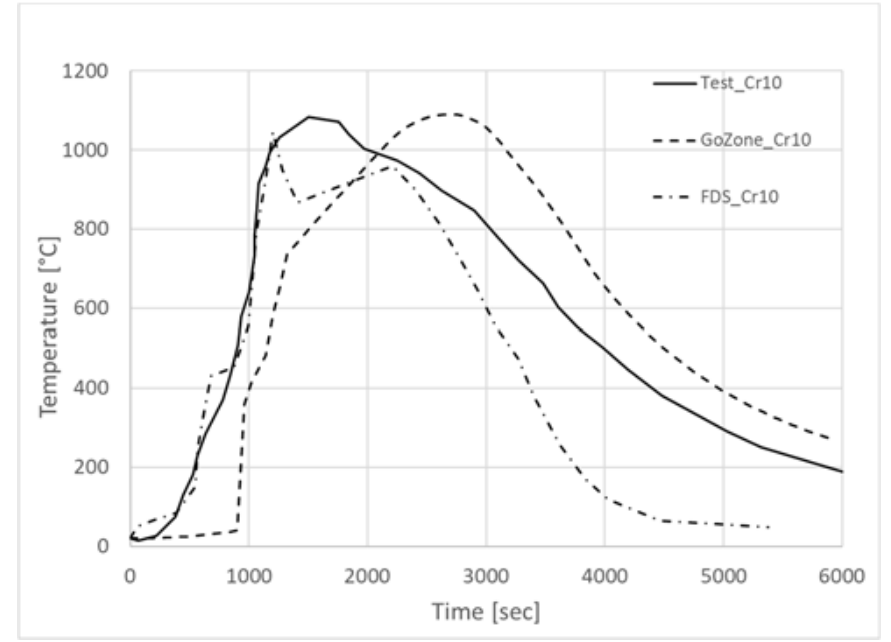

(c)

Figure 19. Gas temperature evolution: GoZone, measured, FDS simulation [22]: (a) Crib line 2; (b) Crib Line 6; (c) Crib line 10.

\section{Comparison with Veselì Travelling Fire Test}

The Veselí fire test was aimed at investigating the fire dynamics and temperature distribution of a fuel controlled fire in a large open compartment in a two-storey building (Czech Republic, 2011) [58]. The compartment size was $10.4 \mathrm{~m} \times 13.4 \mathrm{~m}$ on the floor and $4 \mathrm{~m}$ in height. The fire load was made of wood cribs with sticks of dimensions of $50 \mathrm{~mm} \times 50 \mathrm{~mm} \times 1000 \mathrm{~mm}$ with a moisture content of $12 \%$. A linear channel filled with "petroleum" was used for the ignition of the fire. There was a $5 \mathrm{~m}$ wide and $2 \mathrm{~m}$ high opening in one of the long walls (Figure 20). The gas temperature in the compartment was recorded during the test at different locations whereas the fire behaviour was recorded on camera. Information not directly measured during the test was evaluated numerically by Horova et al. by a CFD based simulation performed with FDS [58]. The test compartment as well as the GoZone model are as shown in Figure 20. 


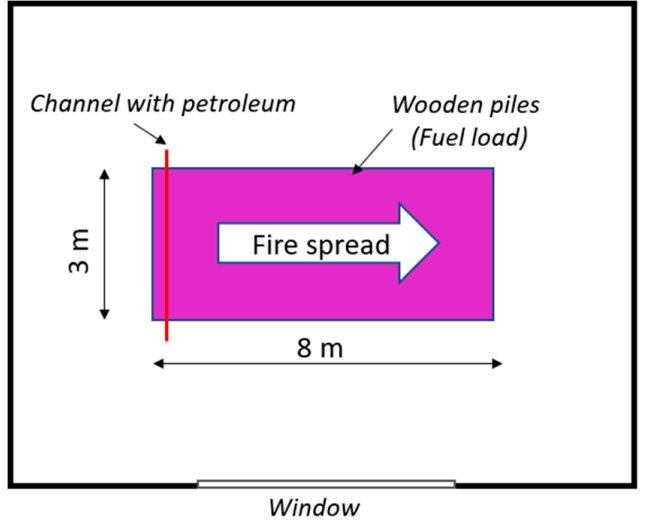

(a)

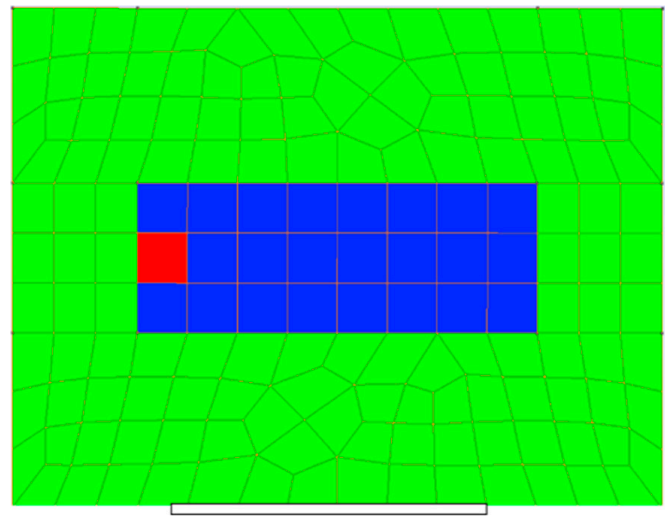

(b)

Figure 20. Plan view of the Veselì fire test: (a) reality; (b) GoZone model.

For the model in GoZone, the fire load area was discretised by a structured mesh with 24 cells of $1 \mathrm{~m}^{2}$ (blue cells in Figure 20b) according to Section 5. The green cells do not contain any fuel and the red cell is the cell of origin of the fire. The comparison with GoZone is meant to be a priori, thus the values of the fuel load density, the rate of the heat release density, and the fire growth rate assigned to the fuel were taken according to the insights given by the authors of the test [49] (see Table 7). The critical energy and the critical heat flux were taken consistently with the outcomes of Section 3.

Table 7. Main input simulation of the Veseli fire test.

\begin{tabular}{ccccc}
\hline $\begin{array}{c}\text { Fuel Load } \\
\text { Density }\left[\mathbf{M J} / \mathbf{m}^{2}\right]\end{array}$ & $\begin{array}{c}\text { Rate of Heat Release } \\
\text { Density }\left[\mathbf{k W} / \mathbf{m}^{2}\right]\end{array}$ & $\begin{array}{c}\text { Fire Growth } \\
\text { Rate }[\mathbf{s}]\end{array}$ & $\begin{array}{c}\text { Critical Energy } \\
{\left[\mathbf{k J} / \mathbf{m}^{2}\right]}\end{array}$ & $\begin{array}{c}\text { Critical Heat } \\
\text { Flux }\left[\mathbf{k W} / \mathbf{m}^{2}\right]\end{array}$ \\
\hline 680 & 700 & 300 & 400 & 12.5 \\
\hline
\end{tabular}

The power released by the fire as a function of time was not directly measured during the test, however, it was evaluated a posteriori by means of the CFD based model with the software FDS [49].

Figure 21 shows the comparison between the results from FDS and GoZone. The peak value of the power as well as the peak time and the total duration were in the same order of magnitude with differences compared to a FDS of $-8 \%,-10 \%$, and $-4 \%$, respectively. A discrepancy can be noticed in the first phase, when FDS accounts for the petroleum burned as means of ignition, which was not the case in GoZone.

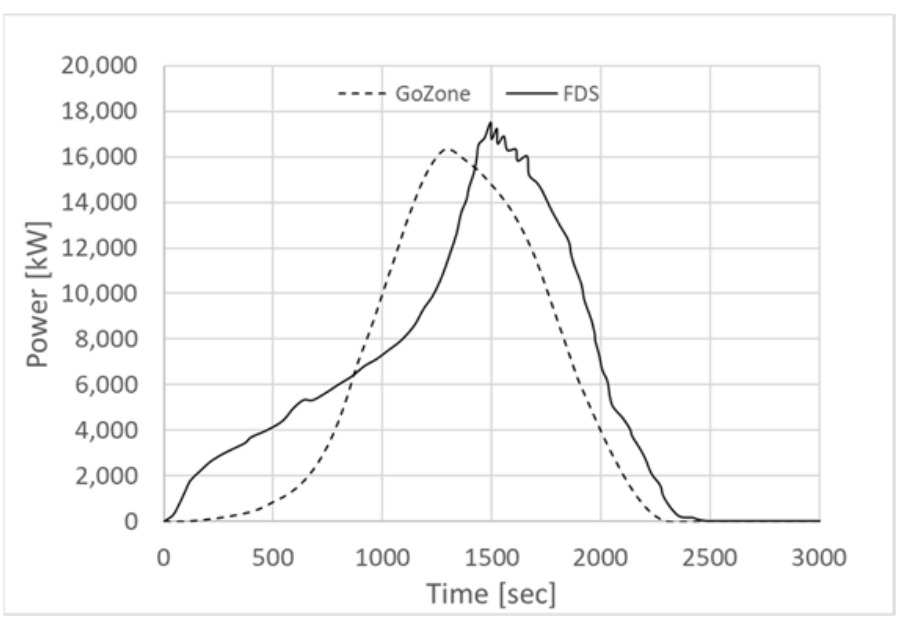

Figure 21. Comparison of the power released in the Veselì fire test. 
The fire evolution has been described by Horova et al. and Dai et al. [49,58,59]. The fire development was characterised by three main phases: phase I, from 0 to 15 min, when the fire leading edge spread along the fuel bed; phase II, from 20 to $25 \mathrm{~min}$, when post-flashover conditions were observed; and phase III, from 25 to $40 \mathrm{~min}$ when the fire trailing edge progressed to the end of the fuel bed, characterised by a decay of the fire. In Figure 22, the fire evolution is shown through a comparison between pictures taken during the test (from Horova et al. [9]) and images from the GoZone Graphical User Interface (GUI). Pink cells represent a fire in its decay phase and black cells are painted where the fuel has been consumed completely.
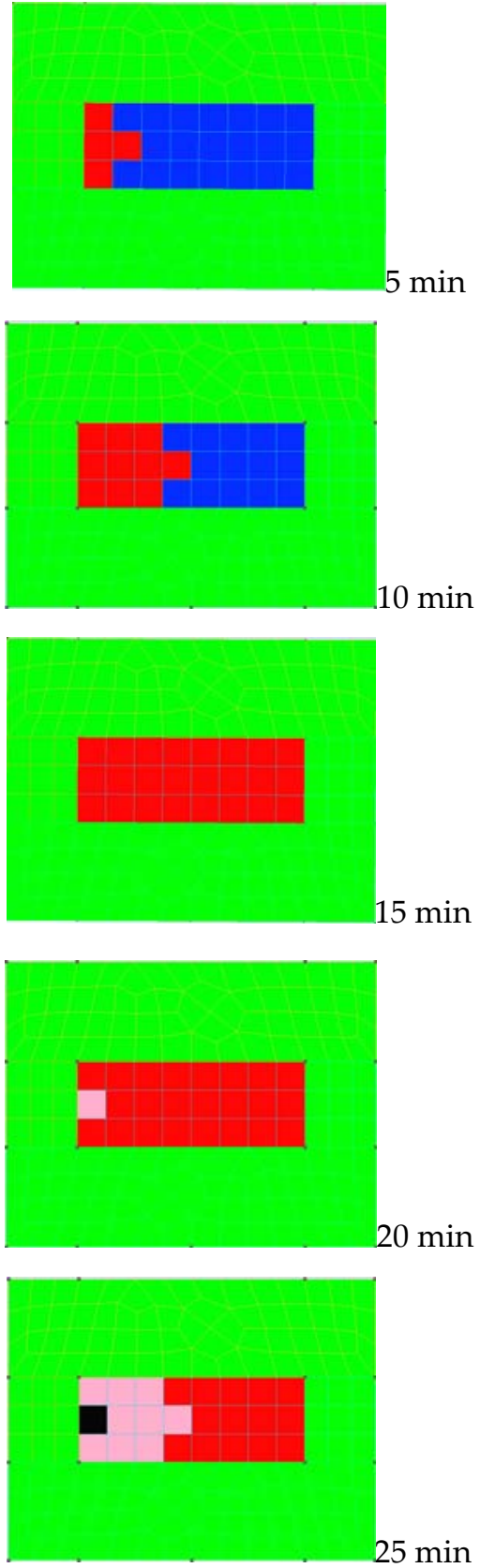

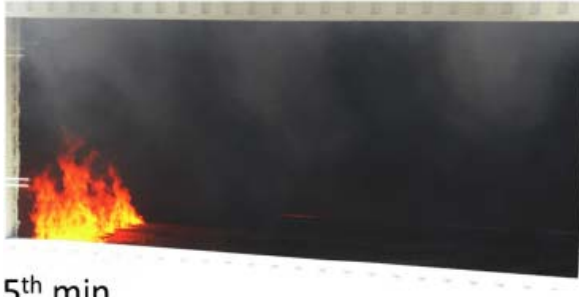

$5^{\text {th }} \min$

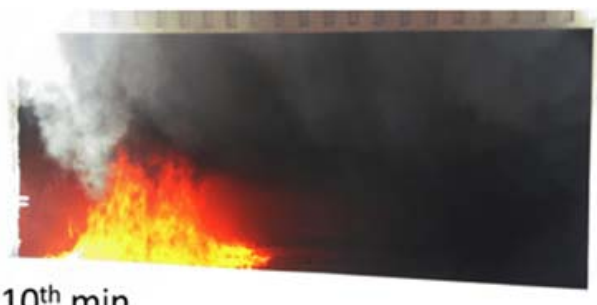
$10^{\text {th }} \min$

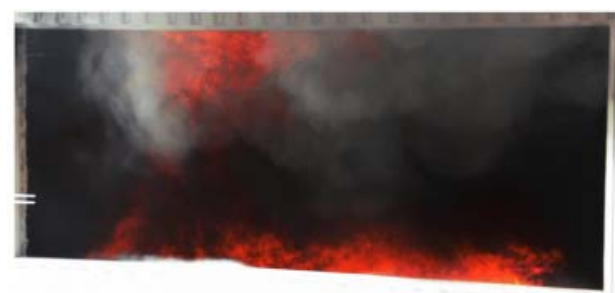

$15^{\text {th }} \min$

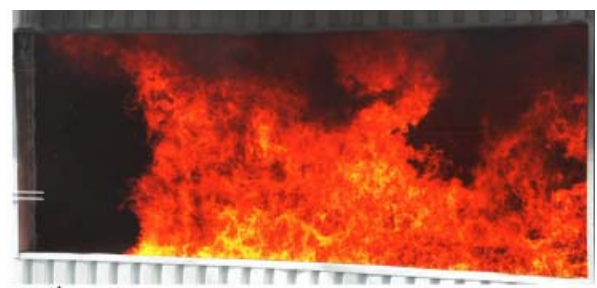
$20^{\text {th }}$ min

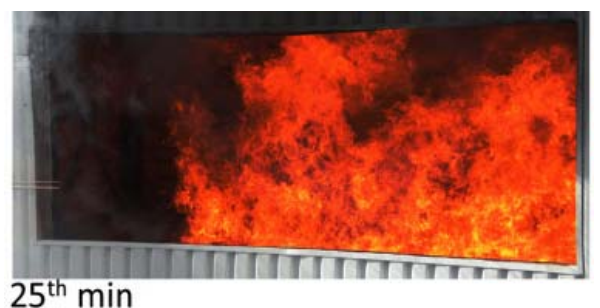

$25^{\text {th }} \min$

Figure 22. Cont. 

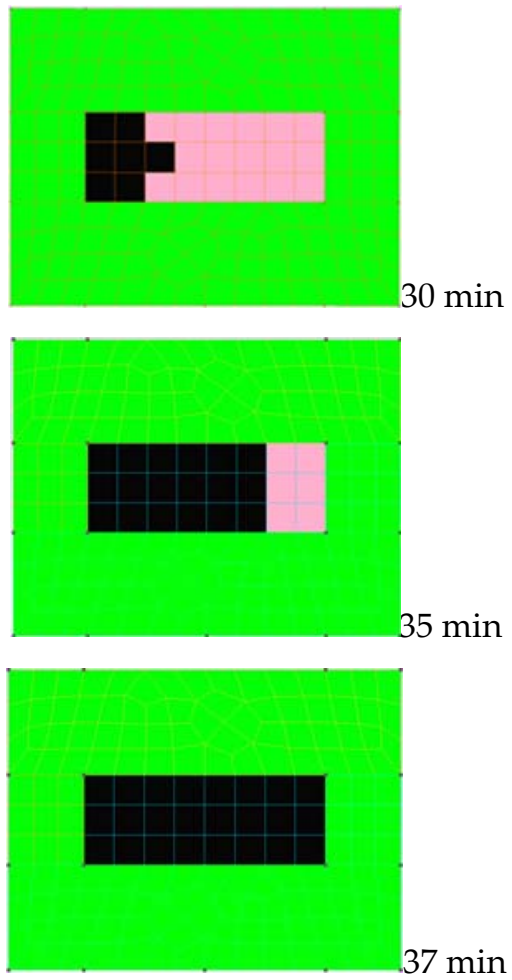

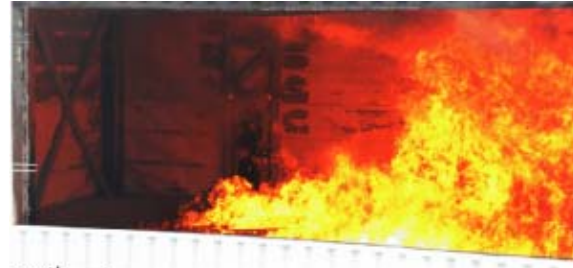

$30^{\text {th }} \min$

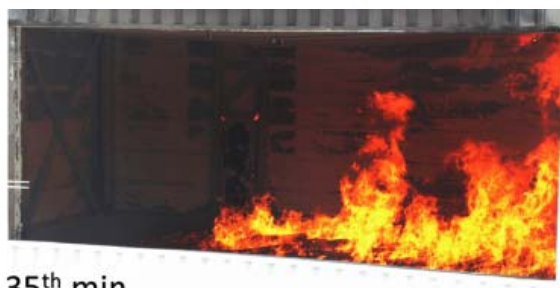

$35^{\text {th }} \min$

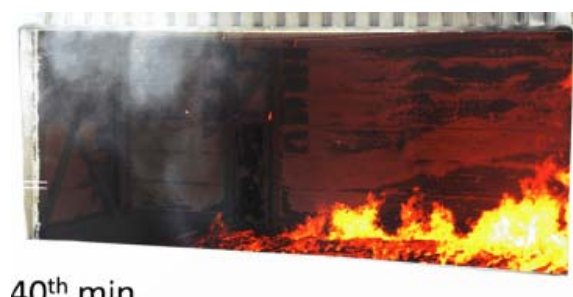

$40^{\text {th }} \min$

Figure 22. Fire evolution: comparison between GoZone (left) and the test (right).

Moreover, it has been observed that the fire spread rate varied during the first phase. Dai et al. [49] provided an estimation of the position of the leading edge of the fire up to the moment when the fire covers the whole fuel bed surface (end of phase I).

Figure 23 shows a comparison between the test and the model for the fire front position in the first phase of the fire; the average fire spread rate in the test, computed from the positions at 5,10 and $15 \mathrm{~min}$, nearly tripled in the third period of $5 \mathrm{~min}$ compared to the initial period, from 3 to $8.9 \mathrm{~mm} / \mathrm{s}$. This figure shows that GoZone is capable of accounting for a variation of fire spread rate depending on the changing fire conditions, in contrast to the travelling fire frameworks proposed in the literature so far, which are all based on a constant spread rate.

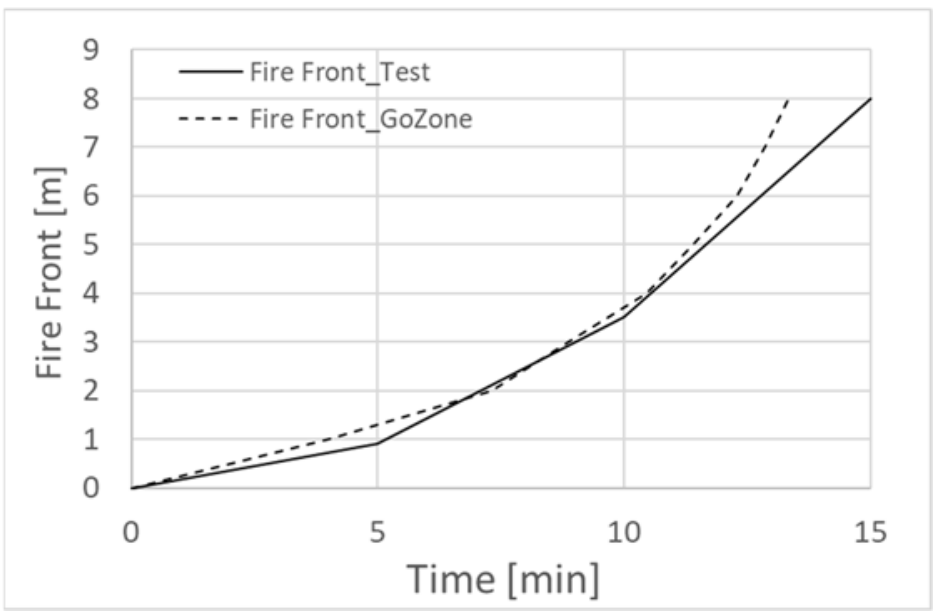

Figure 23. Comparison of thee fire front position between the test and GoZone. 
Gas temperatures at different locations below a steel beam located above the fuel load were also measured. A comparison is given for the two thermocouples indicated in Figure 24 .
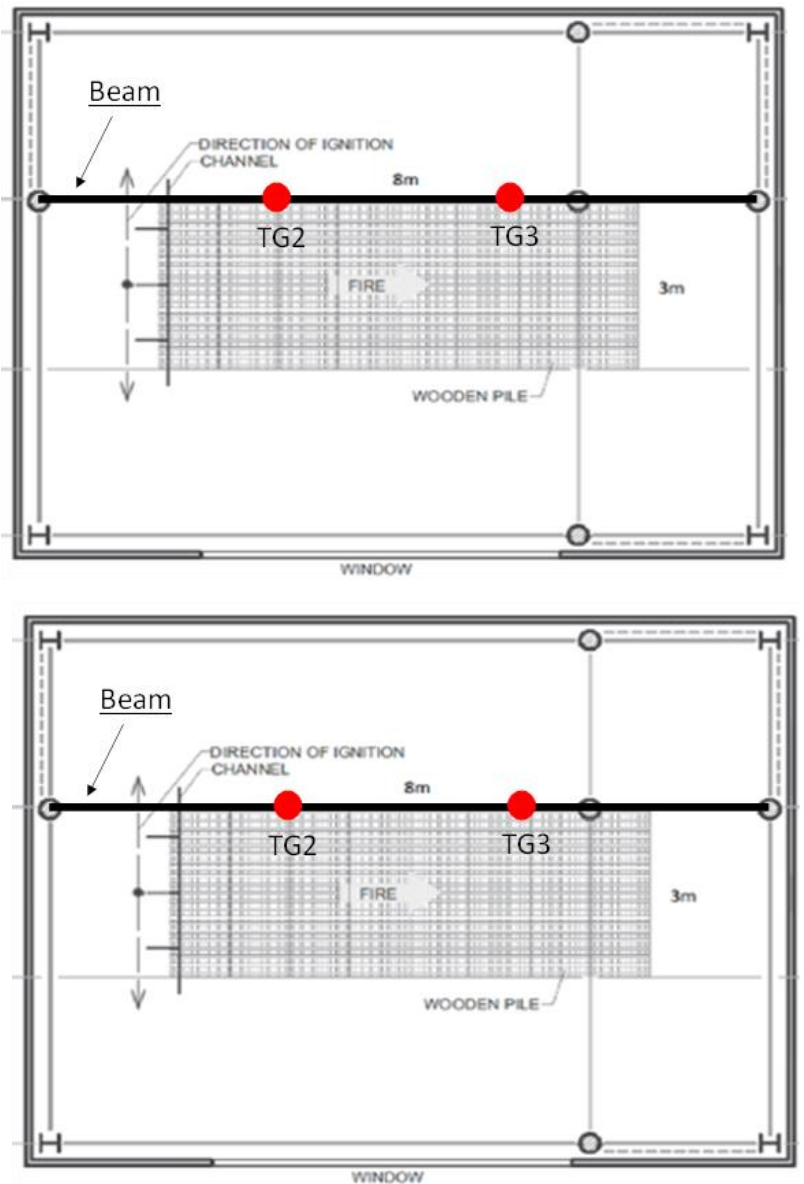

Figure 24. Thermocouple locations.

The gas temperature measured in the test, provided by the GoZone simulation and obtained by the CFD based model of Dai et al. [49] are compared in Figure 25.

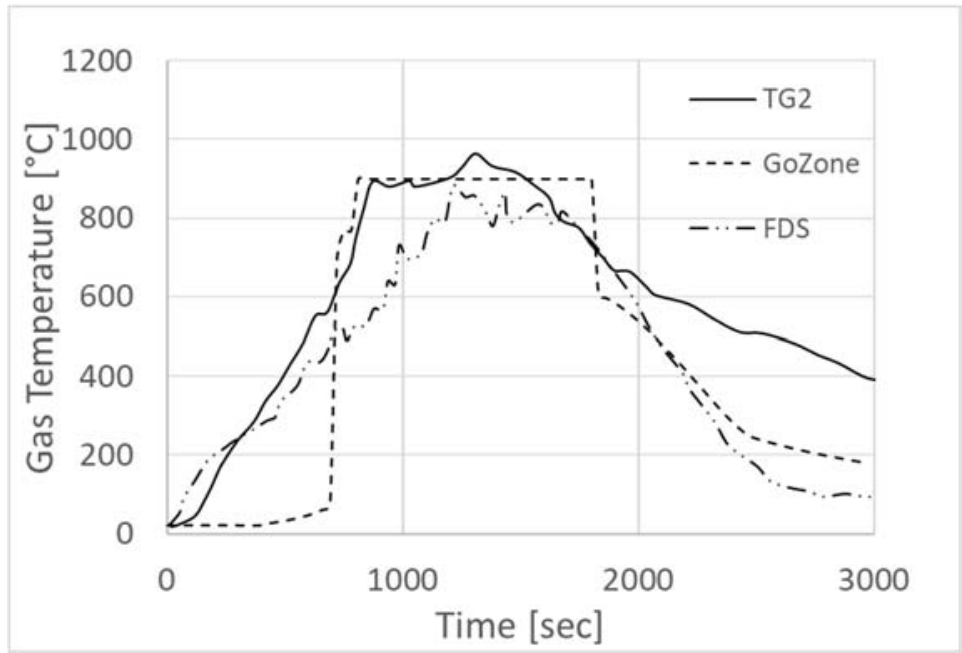

(a)

Figure 25. Cont. 


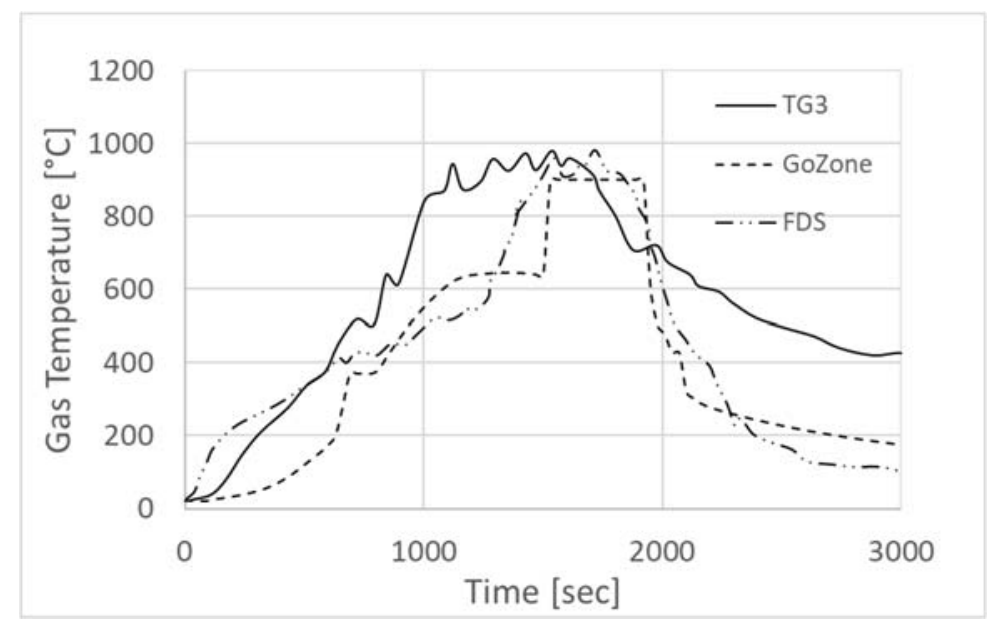

(b)

Figure 25. Gas temperature comparison: (a) TG2; (b) TG3.

Overall, it is possible to observe a reasonable agreement in terms of the predicted gas temperature by both software (at a very different computational cost). However, both FDS and GoZone seem to underestimate the gas temperature in the compartment during the decay phase. The reason for this trend, which has been observed in different occasions, has yet to be identified.

\section{Conclusions}

A numerical model was presented to predict the fire development in compartments. While being based on simplifying assumptions, it proved to have the capability to predict several of the important features of the development of a fire in a compartment from ignition to flashover such as fire propagation and temperature development, in fuel control as well as air control regime. Having the capability to represent several features of the compartment (real shape of the plan view of the floor, real position and surface of any opening) and of the fire load characteristics (density, rate of heat release density, time constant for fire propagation, elevation above ground level, all possibly varying across the compartment, plus any position possible for the fire origin), whereas the run time of current problems on a laptop is in the order of a minute, this model has the ambition to occupy an empty niche between the geometry constrained analytical models presented thus far for travelling fires and the more sophisticated CFD analyses.

The basic idea is to combine an existing two zone model with a discretisation of the floor by a mesh of triangular or quadrilateral cells of finite size, with each cell possibly having its own characteristics with regard to fire load and its own status with regard to combustion. Fire propagation is driven by radiation from burning cells as well as from the hot smoke layer.

Different sub models required particular attention for the development of this tool.

The point source model was adopted to represent the fire source and to compute the radiation that it will generate to the zones of the compartment where combustion has not yet started. Discretisation of the floor and the associated fire load into cells of finite size led to the development of a non-local model concept for computing the flame length in the burning cells. It can be applied to a burning zone of any shape, which is an essential requirement for a model that has the ambition to not be geometrically constrained. This model was tested against an experimental campaign and CFD analyses, which showed good agreement compared with the Heskestad equation in terms of flame length at the centre line of the fire (for shapes of the fire where this equation applies) and it appeared to be almost mesh insensitive for a range of practical mesh sizes.

Radiation from the hot smoke to the fire load was obtained by the discretisation of the lower plane of the hot smoke that was mirrored by the discretisation of the floor and 
computation of the view factors from all cells of the hot smoke to all cells on the floor (with due consideration of possible obstruction in the case of the ground floor with a concave shape or in the case of obstacles present in the compartment such as internal walls).

An ignition strategy was developed based on the concepts of critical energy of ignition and critical heat flux. This strategy has shown reasonably good prediction capabilities including for transient heat flux exposures.

Air control regime is triggered by the total oxygen content in the compartment, and the combustion or not of the different cells is then determined by their proximity to individual openings that deliver air in the compartment.

The model was implemented in the existing OZone model and thus benefits from all capabilities of this model such as the possibility of openings that appear at predefined times or according to defined temperature criteria, the presence of vertical as well as horizontal openings eventually with forced ventilation, and heat loss through the boundaries of the compartment were explicitly considered.

It also had the same inherent limitations such as a horizontal floor and ceiling and a ratio between the characteristic horizontal dimension of the compartment and a floor to ceiling distance that was not excessive.

The new code in which these developments were implemented was given the name of GoZone. The next step will be the automatic transmission of information regarding the results of this fire model to a thermo-mechanical software such as SAFIR ${ }^{\circledR}$, in order to allow for the simulation of the behaviour of a load bearing structure located in the fire compartment.

Author Contributions: Data curation, A.G.; Methodology, A.G. \& J.-M.F.; Software, A.G.; Supervision, J.-M.F.; Writing—original draft, A.G.; Writing—review \& editing, A.G. \& J.-M.F. All authors have read and agreed to the published version of the manuscript.

Funding: This research received no external funding.

Institutional Review Board Statement: Not applicable.

Informed Consent Statement: Not applicable.

Acknowledgments: The work presented in Section 3.3 was carried out in the framework of the TRAFIR project with funding from the Research Fund for Coal and Steel (Grant No. 754198).

Conflicts of Interest: The authors declare no conflict of interest.

\section{Appendix A. Geometrical Capabilities}

This section shows several examples of fire evolution in compartments of complex shape to provide an idea of the geometrical capabilities that the code offers compared to analytical models that are limited to rectangular compartments.
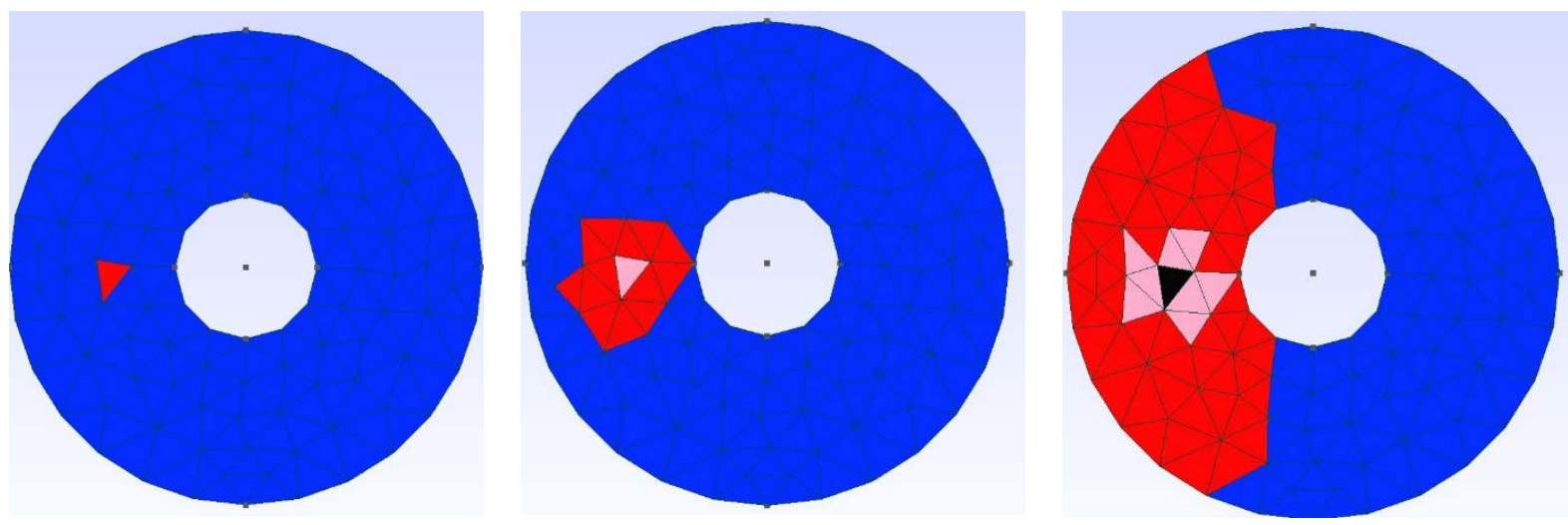

Figure A1. Cont. 

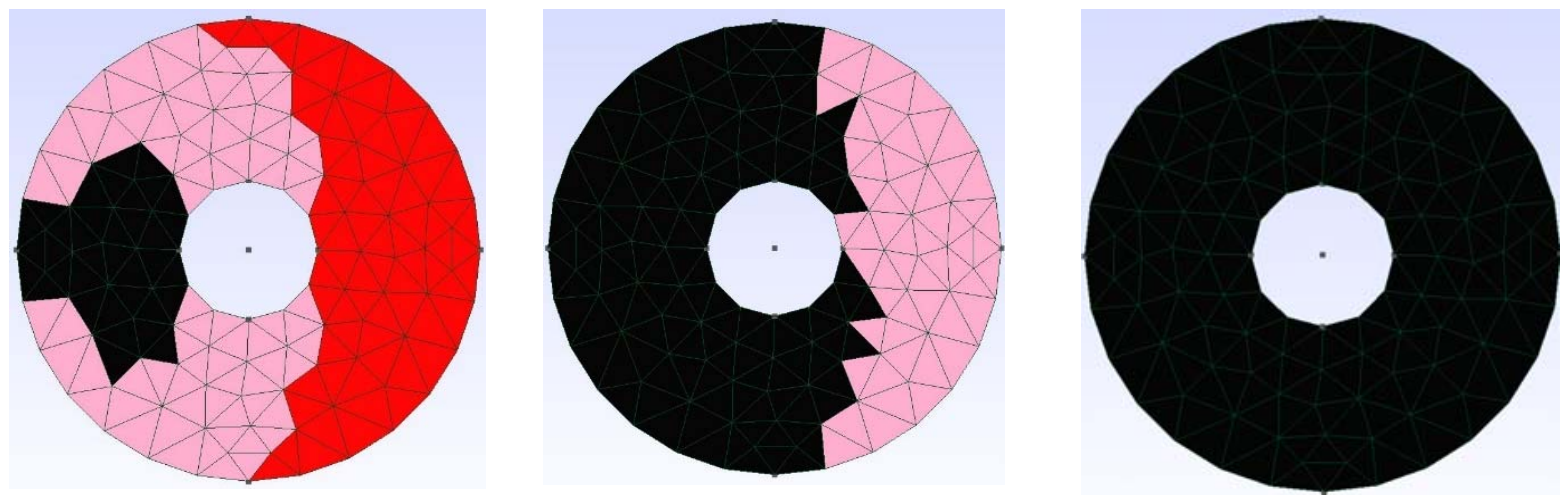

Figure A1. Circular surface with a circular core in the centre. Unstructured triangular mesh (184 elements).
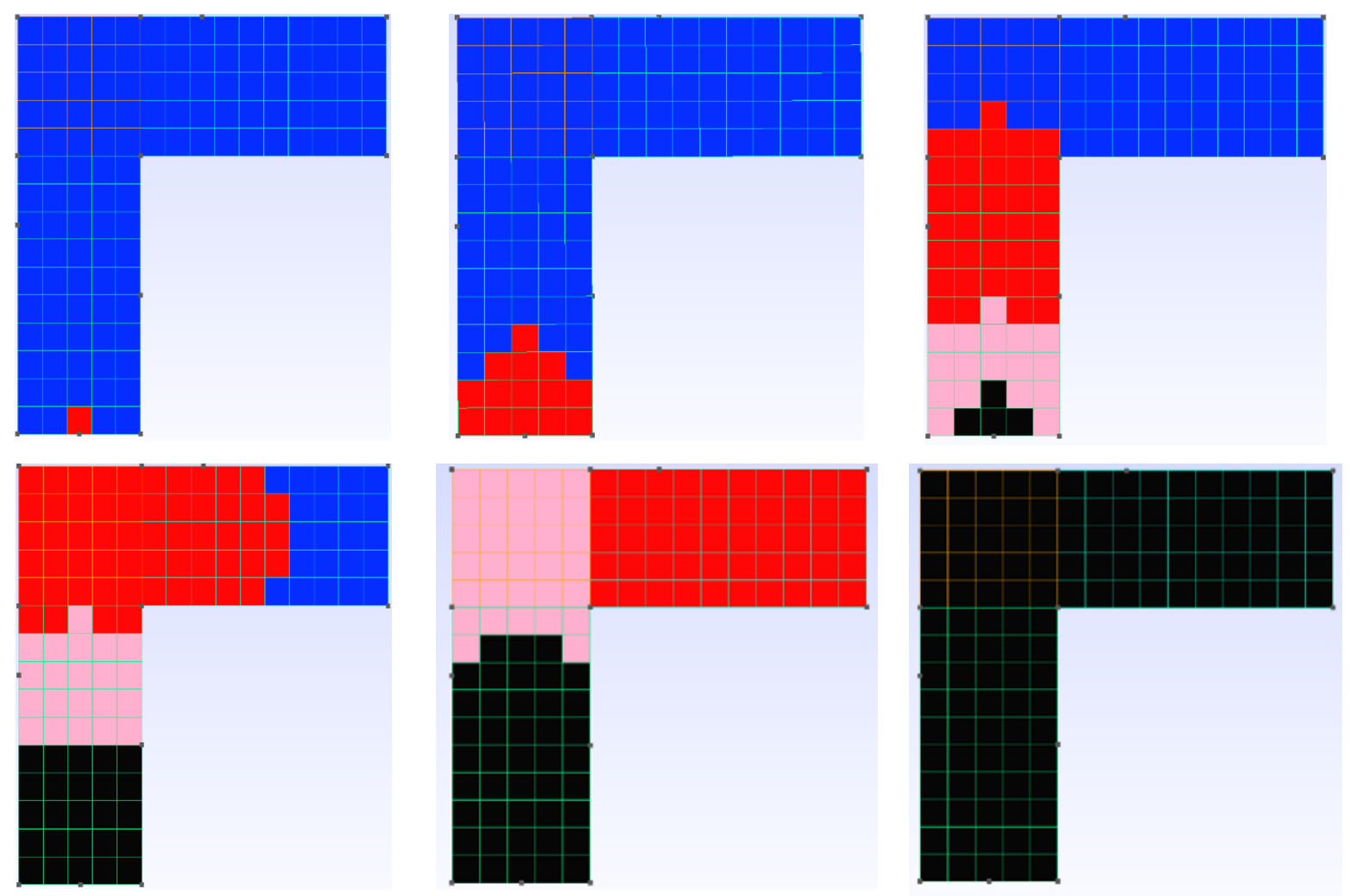

Figure A2. L-Shape geometry. A structured quadrilateral mesh (125 elements).
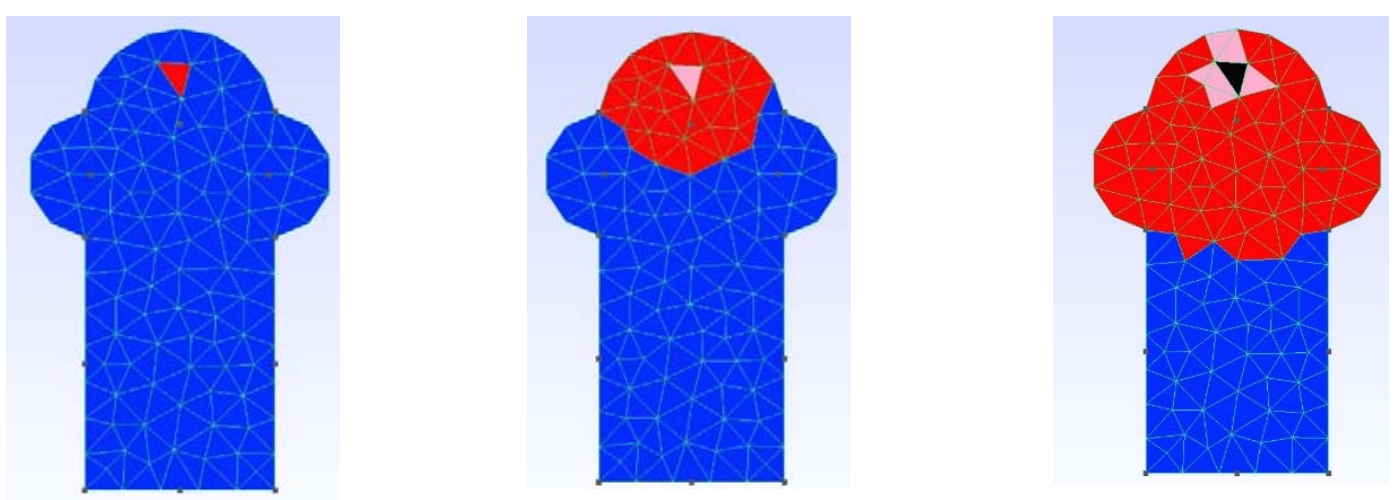

Figure A3. Cont. 

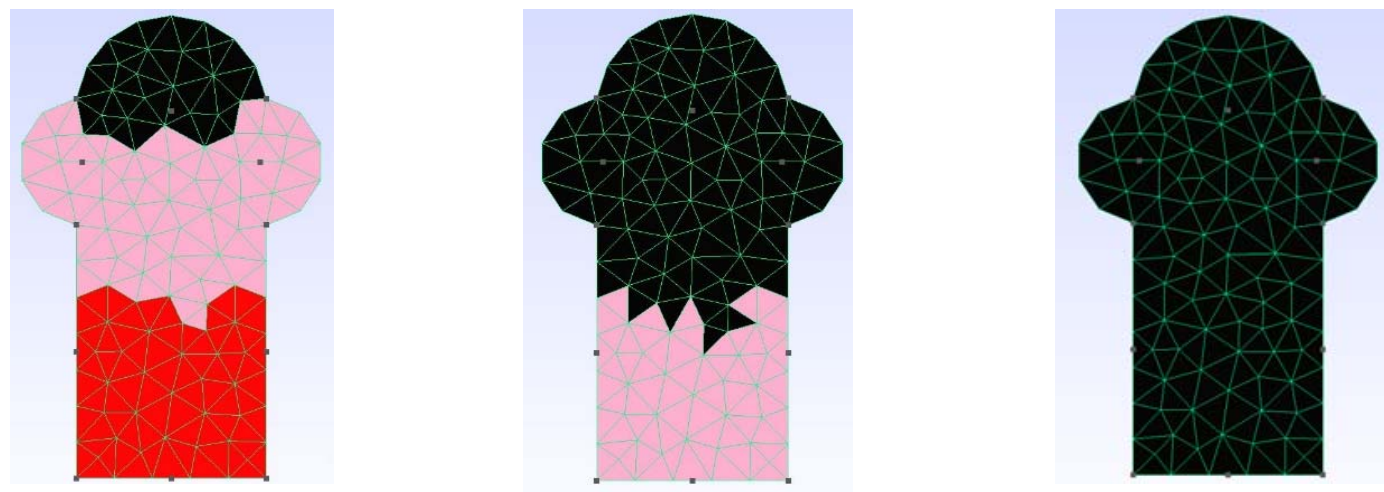

Figure A3. Rectangular shape with circular walls. Unstructured triangular mesh (193 elements).
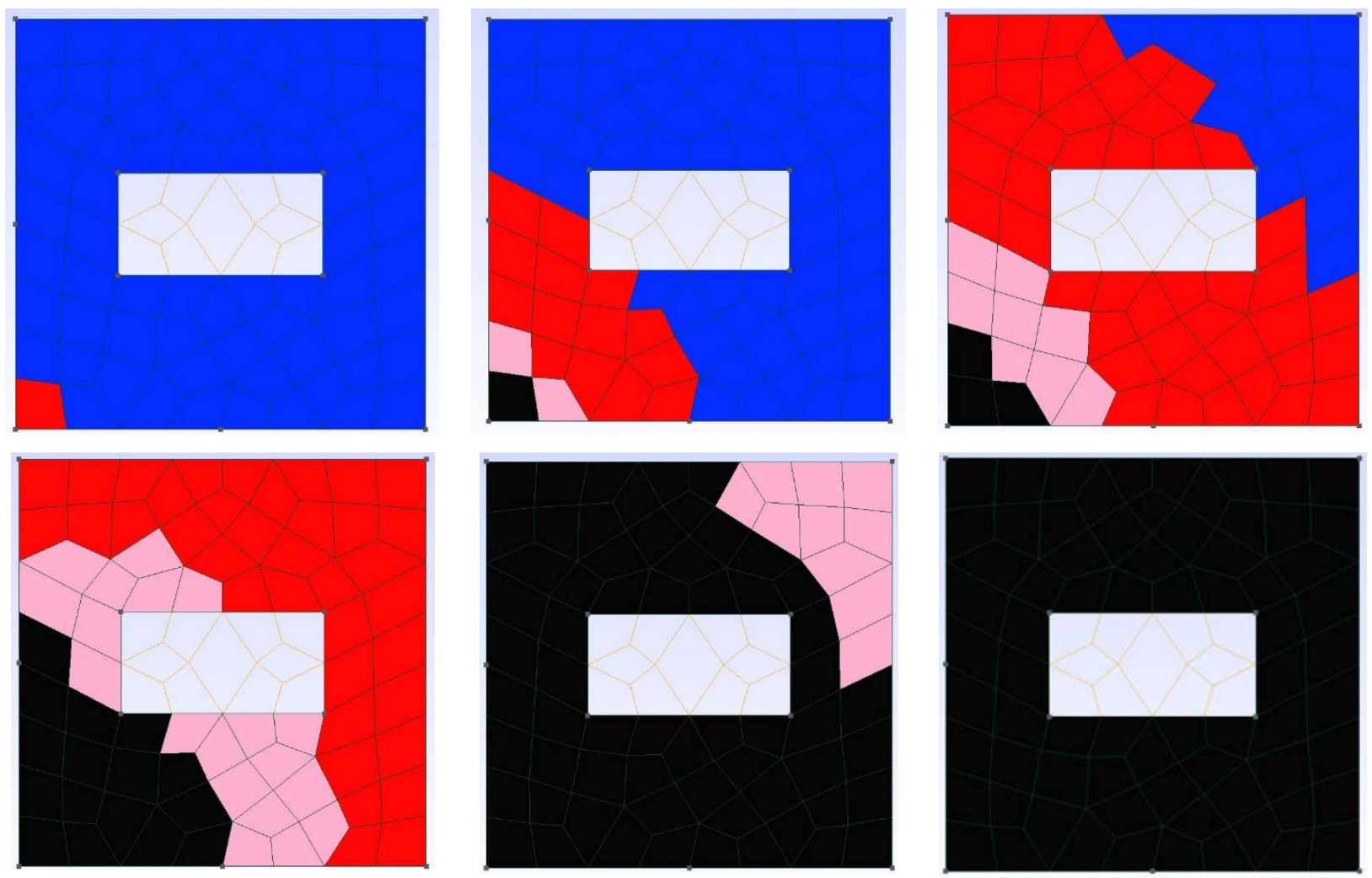

Figure A4. Quadrilateral shape with a rectangular core in the centre. Unstructured quadrilateral mesh (83 elements).

\section{References}

1. Kawagoe, K. Fire Behavior in Rooms. Report 27; Building Research Institute, Ministry of Construction: Tokyo, Japan, 1958.

2. Thomas, P.H.; Heselden, A.J.; Law, M. Fully Developed Compartment Fires-Two Kinds of Behaviour; Fire Research Technical Paper No. 18; H.M. Stationery Office: London, UK, 1967.

3. Harmathy, T.Z. A new look at compartment fires, part I. Fire Technol. 1972, 8, 196-217. [CrossRef]

4. Harmathy, T.Z. A new look at compartment fires, part II. Fire Technol. 1972, 8, 326-351. [CrossRef]

5. Lennon, T.; Moore, D. The natural fire safety concept-Full-scale tests at Cardington. Fire Saf. J. 2003, 38, 623-643. [CrossRef]

6. Stern-Gottfried, J.; Rein, G. Travelling fires for structural design-Part I: Literature review. Fire Saf. J. 2012, 54, 74-85. [CrossRef]

7. Franssen, J.M. SAFIR: A thermal/structural program for modeling structures under fire. Eng. J. 2005, 42, $143-158$.

8. Nakasone, Y.; Yoshimoto, S.; Stolarski, T. Engineering Analysis with ANSYS Software. 2006. Available online: http://gr.xjtu.edu. cn/c/document_library /get_file?folderId=2529162\&name=DLFE-126684.pdf (accessed on 6 November 2021). [CrossRef]

9. Cadorin, J.-F.; Pintea, D.; Dotreppe, J.-C.; Franssen, J.-M. A tool to design steel elements submitted to compartment fires-OZone V2. Part 2: Methodology and application. Fire Saf. J. 2003, 38, 429-451. [CrossRef]

10. Peacock, R.D.; Reneke, P.A.; Forney, G.P. CFAST—Consolidated Model of Fire Growth and Smoke Transport. (Version 7) Volume 1: Technical Reference Guide; National Institute of Standards and Technology: Gaithersburg, MD, USA, 2015. 
11. Heskestad, G. Engineering relations for fire plumes. Fire Saf. J. 1984, 7, 25-32. [CrossRef]

12. Pchelintsev, A.; Hasemi, Y.; Wakarnatsu, T.; Yokobayashi, Y.; Wakamatsu, T. Experimental and Numerical Study on The Behaviour Of A Steel Beam under Ceiling Exposed To A Localized Fire. Fire Saf. Sci. 1997, 5, 1153-1164. [CrossRef]

13. Tondini, N.; Franssen, J.-M. Analysis of experimental hydrocarbon localised fires with and without engulfed steel members. Fire Saf. J. 2017, 92, 9-22. [CrossRef]

14. Tondini, N.; Thauvoye, C.; Hanus, F.; Vassart, O. Development of an analytical model to predict the radiative heat flux to a vertical element due to a localised fire. Fire Saf. J. 2019, 105, 227-243. [CrossRef]

15. McGrattan, K.; Mcdermott, R.; Hostikka, S.; Floyd, J. Fire Dynamics Simulator (Version 5) User's Guide; NIST Special Publication: Gaithersburg, MD, USA, 2010.

16. Clifton, G. Fire Models for Large Firecells; HERA Rep. R4-83 C; HERA: London, UK, 1996; 124p.

17. Wang, Y.; Burgess, I.; Wald, F.; Gillie, M. Performance-Based Fire Engineering of Structures; CRC Press: London, UK, 2012.

18. Rein, G.; Zhang, X.; Williams, P.; Hume, B.; Heise, A. Multi-Storey Fire Analysis for High-Rise Buildings, 11th Interflam; Interflam: London, UK, 2007; pp. 605-616.

19. Rackauskaite, E.; Hamel, C.; Rein, G. Improved Travelling Fires Methodology-iTFM. Appl. Struct. Fire Eng. 2016. [CrossRef]

20. Dai, X.; Welch, S.; Usmani, A. A critical review of "travelling fire" scenarios for performance-based structural engineering. Fire Saf. J. 2017, 91, 568-578. [CrossRef]

21. Kirby, B.; Wainman, D.; Tomlinson, L.; Kay, T.; Peacock, B. Natural Fires in Large Scale Compartments. Int. J. Eng. Perform.-Based Fire Codes 1999, 1, 43-58.

22. Dai, X.; Welch, S.; Rush, D.; Charlier, M.; Anderson, J. Characterising natural fires in large compartments-Revisiting an early travelling fire test (BST/FRS 1993) with CFD. In Proceedings of the 15th International Interflam Conference, London, UK, 1-3 July 2019; p. 12.

23. Von Neumann, J. The General and Logical Theory of Automata. In Cerebral Mechanisms in Behavior: The Hixon Symposium; Jeffress, L.A., Ed.; John Wiley \& Sons: New York, NY, USA, 1951; pp. 1-41.

24. Wolfram, S. Statistical mechanics of cellular automata. Rev. Mod. Phys. 1983, 55, 601-644. [CrossRef]

25. Quartieri, J.; Mastorakis, N.E.; Iannone, G.; Guarnaccia, C. A Cellular Automata model for fire spreading prediction. Int. Conf. Urban Plan. Transp.-Proc. 2010, 1, 173-179.

26. Hargrove, W.; Gardner, R.; Turner, M.; Romme, W.; Despain, D. Simulating fire patterns in heterogeneous landscapes. Ecol. Model. 2000, 135, 243-263. [CrossRef]

27. Clarke, K.C.; Brass, J.A.; Riggan, P.J. A cellular automaton model of wildfire propagation and extinction. Photogramm. Eng. Remote Sens. 1994, 60, 1355-1367.

28. Geuzaine, J.F.; Remacle, C. Gmsh: A Three-Dimensional Finite Element Mesh Generator with Built-in Pre- and Post-Processing. Facil. Int. J. Numer. Meth. Eng. 2009, 79, 1309-1331. [CrossRef]

29. Hill, H.B.; Comey, A.M. On the Behavior of Sound and Decayed Wood at High Temperatures. Proc. Am. Acad. Arts Sci. 1886, 22, 482. [CrossRef]

30. Brown, C.R. The Determination of the Ignition Temperatures of Solid Materials; University of Michigan: Ann Arbor, MI, USA, 1934; Available online: https://books.google.be/books/about/The_Determination_of_the_Ignition_Temper.html?id=UU3 PAAAAMAAJ\&redir_esc=y (accessed on 20 July 2021).

31. Browne, F. Ignition and Charring Temperautres of Wood; Report, No.1464; Forest Products Laboratory, Forest Service, U. S. Department of Agriculture: Madison, WI, USA, 1958.

32. Fangrat, J.; Hasemi, Y.; Yoshida, M.; Hirata, T. Surface temperature at ignition of wooden based slabs. Fire Saf. J. 1996, 27, 249-259. [CrossRef]

33. Shoub, H.; Bender, E.W. Radiant Ignition of Wall Finish Materials in a Small Home; U. S. Department of Commerce National Bureau of Standards: Gaithersburg, MD, USA, 1964. [CrossRef]

34. Babrauskas, V. Ignition of Wood: A Review of the State of the Art. J. Fire Prot. Eng. 2002, 12, 163-189. [CrossRef]

35. Bluhme, D.A. ISO ignitability test and proposed criteria. Fire Mater. 1987, 11, 195-199. [CrossRef]

36. Mikkola, E. Ignitability Comparisons between the ISO Ignitability Test and the Cone Calorimeter. J. Fire Sci. 1991, 9, 276-284. [CrossRef]

37. Silcock, G.; Shields, T. A protocol for analysis of time-to-ignition data from bench scale tests. Fire Saf. J. 1995, 24, 75-95. [CrossRef]

38. Shields, T.J.; Silcock, G.W.; Murray, J.J. Evaluating ignition data using the flux time product. Fire Mater. 1994, 18, 243-254. [CrossRef]

39. Janssens, M. A thermal model for piloted ignition of wood including variable thermophysical properties. In Fire Safety ScienceProceedings of the Third International Symposium; International Association for Fire Safety Science: London, UK, 2006. [CrossRef]

40. Harada, T. Time to ignition, heat release rate and fire endurance time of wood in cone calorimeter test. Fire Mater. 2001, 25, 161-167. [CrossRef]

41. Bilbao, R.; Mastral, J.F.; Lana, J.A.; Ceamanos, J.; Aldea, M.E.; Betrán, M. A model for the prediction of the thermal degradation and ignition of wood under constant and variable heat flux. J. Anal. Appl. Pyrolysis 2002, 62, 63-82. [CrossRef]

42. Ji, J.; Cheng, Y.; Yang, L.; Guo, Z.; Fan, W. An Integral Model for Wood Auto-ignition under Variable Heat Flux. J. Fire Sci. 2006, 24, 413-425. [CrossRef] 
43. Welch, S.; Marshall, N.R. Development and validation of a comprehensive model for flame spread and toxic products in full-scale scenarios. In 4th International Seminar on Fire and Explosion Hazards; University of Edinburgh: Edinburgh, UK, 2004; pp. 259-270.

44. Gamba, A.; Charlier, M.; Franssen, J.-M. Propagation tests with uniformly distributed cellulosic fire load. Fire Saf. J. 2020, 117, 103213. [CrossRef]

45. CEN-European Committee for Standardization. EN 1995-1-2:2004, Eurocode 5-Design of Timber Structures Part 1-2: GeneralStructural fire Design; CEN_European Committee for Standardization: Bruxelles, Belgium, 2004.

46. Spearpoint, M.; Quintiere, J. Predicting the piloted ignition of wood in the cone calorimeter using an integral model—Effect of species, grain orientation and heat flux. Fire Saf. J. 2001, 36, 391-415. [CrossRef]

47. CEN-European Committee for Standardization. EN 1991-1-2, Eurocode 1: Actions on Structures_Part 1-2: General Actions-Actions on Structures Exposed to Fire; CEN-European Committee for Standardization: Bruxelles, Belgium, 2002. [CrossRef]

48. Karlsson, B.; Quintiere, J. Enclosure Fire Dynamics; CRC Press:: Boca Raton, FL, USA, 1999. [CrossRef]

49. Dai, X.; Welch, S.; Vassart, O.; Cábová, K.; Jiang, L.; Maclean, J.; Clifton, G.C.; Usmani, A. An extended travelling fire method framework for performance-based structural design. Fire Mater. 2020, 44, 437-457. [CrossRef]

50. Lautenberger, C.; Tien, C.L.; Lee, K.Y.; Stretton, A.J. Radiation Heat Transfer. In SFPE Handbook Fire Protection Engineering, 5th ed.; Springer: New York, NY, USA, 2016; pp. 102-135. [CrossRef]

51. Modak, A.T. Thermal radiation from pool fires. Combust. Flame 1977, 29, 177-192. [CrossRef]

52. Drysdale, D. An Introduction to Fire Dynamics, 2nd ed.; Wiley: Chichester, UK, 2011; ISBN 9781119975465.

53. Casal, J. Evaluation of the Effects and Consequences of Major Accidents in Industrial Plants, 2nd ed.; Elsevier: Amsterdam, The Netherlands, 2017; ISBN 978-0-444-63883-0. [CrossRef]

54. Fleury, R. Evaluation of Thermal Radiation Models for Fire Spread between Objects. Ph.D. Thesis, University of Canterbury, Christchurch, New Zealand, 2011.

55. Heskestad, G. Flame Heights of Fuel Arrays with Combustion in Depth. Fire Saf. Sci. 1997, 5, 427-438. [CrossRef]

56. de Sciarra, F.M. A nonlocal model with strain-based damage. Int. J. Solids Struct. 2009, 46, 4107-4122. [CrossRef]

57. Cadorin, J.-F.; Franssen, J.-M. A tool to design steel elements submitted to compartment fires-OZone V2. Part 1: Pre- and post-flashover compartment fire model. Fire Saf. J. 2003, 38, 395-427. [CrossRef]

58. Horová, K.; Wald, F.; Bouchair, A. Travelling Fire in Full-Scale Experimental Building. Design Fabr. Econ. Metal. Struct. 2013, 371-376. [CrossRef]

59. Horová, K.; Jána, T.; Wald, F. Temperature heterogeneity during travelling fire on experimental building. Adv. Eng. Softw. 2013, 62-63, 119-130. [CrossRef] 